\title{
SNPC-1.3 is a sex-specific transcription factor that drives male piRNA expression in C. elegans
}

\section{Charlotte P Choi ${ }^{1+}$, Rebecca J Tay ${ }^{1 \dagger}$, Margaret R Starostik ${ }^{1}$, Suhua Feng ${ }^{2,3}$, James J Moresco ${ }^{4}$, Brooke E Montgomery ${ }^{5}$, Emily Xu', Maya A Hammonds ${ }^{1}$, Michael C Schatz ${ }^{1,6}$, Taiowa A Montgomery ${ }^{5}$, John R Yates III, Steven E Jacobsen ${ }^{2,8}$, John K Kim ${ }^{1 *}$}

${ }^{1}$ Department of Biology, Johns Hopkins University, Baltimore, United States; ${ }^{2}$ Department of Molecular, Cell and Developmental Biology, University of California, Los Angeles, Los Angeles, United States; ${ }^{3}$ Eli and Edythe Broad Center of Regenerative Medicine and Stem Cell Research, University of California, Los Angeles, Los Angeles, United States; ${ }^{4}$ Center for the Genetics of Host Defense, University of Texas Southwestern Medical Center, Dallas, United States; ${ }^{5}$ Department of Biology, Colorado State University, Fort Collins, United States; ${ }^{6}$ Department of Computer Science, Johns Hopkins University, Baltimore, United States; ${ }^{7}$ Department of Molecular Medicine, The Scripps Research Institute, La Jolla, United States; ${ }^{8}$ Howard Hughes Medical Institute, University of California, Los Angeles, Los Angeles, United States

Abstract Piwi-interacting RNAs (piRNAs) play essential roles in silencing repetitive elements to promote fertility in metazoans. Studies in worms, flies, and mammals reveal that piRNAs are expressed in a sex-specific manner. However, the mechanisms underlying this sex-specific regulation are unknown. Here we identify SNPC-1.3, a male germline-enriched variant of a conserved subunit of the small nuclear RNA-activating protein complex, as a male-specific piRNA transcription factor in Caenorhabditis elegans. SNPC-1.3 colocalizes with the core piRNA transcription factor, SNPC-4, in nuclear foci of the male germline. Binding of SNPC-1.3 at male piRNA loci drives spermatogenic piRNA transcription and requires SNPC-4. Loss of snpc-1.3 leads to depletion of male piRNAs and defects in male-dependent fertility. Furthermore, TRA-1, a master regulator of sex determination, binds to the snpc-1.3 promoter and represses its expression during oogenesis. Loss of TRA-1 targeting causes ectopic expression of snpc-1.3 and male piRNAs during oogenesis. Thus, sexually dimorphic regulation of snpc-1.3 expression coordinates male and female piRNA expression during germline development.

\section{Introduction}

Piwi-interacting RNAs (piRNAs), a distinct class of small noncoding RNAs, function to preserve germline integrity (Batista et al., 2008; Carmell et alı, 2007; Cox et al., 1998; Deng and Lin, 2002; Kuramochi-Miyagawa et al., 2008; Lin and Spradling, 1997; Wang and Reinke, 2008). In Drosophila, mutation of any of the three Piwi genes (piwi, aub, ago3) results in rampant activation of transposons in the germline and severe defects in fertility (Brennecke et al., 2007; Harris and Macdonald, 2001; Lin and Spradling, 1997; Vagin et al., 2006). In Mus musculus, mutation of the Piwi protein MIWI leads to the misregulation of genes involved in germ cell development, defective gametogenesis, and sterility (Deng and Lin, 2002; Zhang et al., 2015b). Caenorhabditis elegans piRNAs can 
be inherited across multiple generations and trigger the transgenerational silencing of foreign elements such as transgenes. Disruption of this inheritance results in eventual germline collapse and sterility, known as the germline mortal phenotype (Ashe et al., 2012; Buckley et al., 2012; Shirayama et al., 2012). Taken together, piRNAs are essential to preserve germline integrity and ensure the reproductive capacity in metazoans.

Loss of the piRNA pathway can have distinct consequences between the sexes and across developmental stages. Many species show sex-specific expression of piRNAs (Armisen et al., 2009; Billi et al., 2013; Williams et al., 2015; Yang et al., 2013; Zhou et al., 2010). Demonstrated by hybrid dysgenesis, the identity of maternal, but not paternal, piRNAs in flies is important for fertility of progeny (Brennecke et al., 2008). In contrast, the piRNA pathway in mammals appears to be dispensable for female fertility (Carmell et al., 2007; Murchison et al., 2007), but distinct subsets of piRNAs are required for specific stages of spermatogenesis (Aravin et al., 2003; Aravin et alı, 2006; Carmell et alı, 2007; Di Giacomo et alı, 2013; Gainetdinov et alı, 2018; Girard et al., 2006; Grivna et al., 2006; Kuramochi-Miyagawa et alı, 2008; Li et alo, 2013). In worms, most piRNAs are uniquely enriched in either the male or female germline (Billi et alo, 2013; Kato et al., 2009). Nevertheless, in all of these contexts, how the specific expression of different piRNA subclasses is achieved is poorly understood.

piRNA biogenesis is strikingly diverse across organisms and tissue types. In the Drosophila germline, piRNA clusters are found within pericentromeric or telomeric heterochromatin enriched for H3K9me3 histone modifications. The HP1 homolog Rhino binds to H3K9me3 within most of these piRNA clusters and recruits Moonshiner, a paralog of the basal transcription factor TFIIA, which, in turn, recruits RNA polymerase II (Pol II) to enable transcription within heterochromatin (Andersen et alo, 2017; Chen et alo, 2016; Klattenhoff et alo, 2009; Mohn et alo, 2014; Pane et al., 2011). Two waves of piRNA expression occur in mouse testes: pre-pachytene piRNAs are expressed in early spermatogenesis and silence transposons, whereas pachytene piRNAs are expressed in the later stages of meiosis and have unknown functions. While the mechanisms of prepachytene piRNA transcription remain elusive, pachytene piRNAs require the transcription factor A-MYB, along with RNA Pol II (Li et al., 2013).

In C. elegans, SNPC-4 is essential for the expression of piRNAs in the germline (Kasper et al., 2014). SNPC-4 is the single C. elegans ortholog of mammalian SNAPC4, the largest DNA binding subunit of the small nuclear RNA (snRNA) activating protein complex (SNAPc). A complex of SNAPC4, SNAPC1, and SNAPC3 binds to the proximal sequence element (PSE) of snRNA loci to promote their transcription (Henry et alo, 1995; Jawdekar and Henry, 2008; Ma and Hernandez, 2002; Su et alo, 1997; Wong et alo, 1998; Yoon et alo, 1995). SNPC-4 occupies transcription start sites of other classes of noncoding RNAs across various $C$. elegans tissue types and developmental stages (Kasper et alo, 2014; Weng et al., 2019). Furthermore, piRNA biogenesis factors PRDE-1, TOFU-4, and TOFU-5 are expressed in germ cell nuclei and interact with SNPC-4 at clusters of piRNA loci (Goh et alo, 2014; Kasper et alo, 2014; Weick et alı, 2014; Weng et alo, 2019). These data suggest that SNPC-4 has been co-opted by germline-specific factors to transcribe piRNAs.

The vast majority of the $\sim 15,000$ piRNAs in C. elegans are encoded within two large megabase genomic clusters on chromosome IV (Das et al., 2008; Ruby et al., 2006). Each piRNA locus encodes a discrete transcriptional unit that is individually transcribed as a short precursor by Pol II (Gu et al., 2012; Cecere et al., 2012; Billi et al., 2013). Processing of precursors yields mature piRNAs that are typically 21 nucleotides (nt) in length and strongly enriched for a $5^{\prime}$ uracil (referred to as 21U-RNAs). Transcription of these piRNAs requires a conserved eight nt core motif (NNGTTTCA) within their promoters (Billi et al., 2013; Cecere et al., 2012; Ruby et al., 2006). piRNAs enriched during spermatogenesis are associated with a cytosine at the $5^{\prime}$ most position of the core motif (CNGTTTCA); mutation of cytosine to adenine at this position results in ectopic expression of normally male-enriched piRNAs during oogenesis. In contrast, genomic loci expressing piRNAs enriched in the female germline show no discernable nucleotide bias at the $5^{\prime}$ position (Billi et alo, 2013). While differences in cis-regulatory sequences contribute to the sexually dimorphic nature of piRNA expression, sex-specific piRNA transcription factors that drive distinct subsets of piRNAs in the male and female germlines remain to be identified.

Here, we demonstrate that SNPC-1.3, an ortholog of human SNAPC1, is required specifically for male piRNA expression. Furthermore, TRA-1, a master regulator of sex determination, transcriptionally represses snpc-1.3 during oogenesis to restrict its expression to the male germline. Taken 
together, our study reports the first example of a sex-specific piRNA transcription factor that drives the expression of male-specific piRNAs.

\section{Results}

\section{SNPC-4 is a component of the core piRNA transcription complex that drives all piRNA expression}

SNPC-4-specific foci are present in both male and female germ cell nuclei (Kasper et al., 2014), but the role of SNPC-4 in the male germline is not well understood. We hypothesized that SNPC-4 is required for piRNA biogenesis in both the male and female germline. To test this, we conditionally depleted the SNPC-4 protein using the auxin-inducible degradation system (Zhang et alo, 2015a; Figure 1-figure supplement 1A). We added an auxin-inducible degron (AID) to the C-terminus of SNPC-4 using CRISPR/Cas9 genome engineering, and crossed this strain into worms expressing TIR1 under the germline promoter, sun-1. TIR1 is a plant-specific F-box protein that mediates the rapid degradation of $C$. elegans proteins tagged with an AID in the presence of the phytohormone auxin. Thus, addition of auxin to the snpc-4::aid; Psun-1::TIR1 strain is expected to degrade SNPC4::AID, whereas strains with snpc-4::aid alone serve as a negative control; under these conditions, we examined a panel of spermatogenesis- and oogenesis-enriched piRNAs (Billi et al., 2013) during spermatogenesis and oogenesis. Unless otherwise stated, spermatogenesis and oogenesis stages will correspond to time points taken at $48 \mathrm{hr}$ and $72 \mathrm{hr}$, respectively, post-L1 hatching at $20^{\circ} \mathrm{C}$. Worms depleted of SNPC-4 showed decreased expression of both spermatogenesis- and oogenesis-enriched piRNAs during spermatogenesis and oogenesis time points, respectively (Figure 1A), confirming that SNPC-4 is a core piRNA transcription factor required for all piRNA expression.

Given that SNPC-4 activates transcription of piRNAs in both sexes, we hypothesized that sex-specific cofactors might associate with SNPC-4 to regulate sexually dimorphic piRNA expression. To test this hypothesis, we leveraged genetic backgrounds that masculinize or feminize the germline. Specifically, we used him-8(-) mutants, which have a higher incidence of males ( $30 \%$ males compared to $<0.5 \%$ spontaneous males in the wild-type hermaphrodite population) (Hodgkin et al., 1979), and fem-1(-) mutants, which are completely feminized when grown at $25^{\circ} \mathrm{C}$ (Doniach and Hodgkin, 1984). We introduced a C-terminal 3xFlag tag sequence at the endogenous snpc-4 locus using CRISPR/Cas9 genome editing (Paix et alo, 2015) and performed immunoprecipitation of SNPC-4::3xFlag followed by mass spectrometry. PRDE-1 and TOFU-5 co-purified with SNPC4::3xFlag in both him-8(-) and fem-1(-) mutants, suggesting that these known piRNA biogenesis factors exist as a complex in both male and female germlines (Figure 1B, $C$, Figure 1-figure supplement 1B). While a single worm ortholog, SNPC-4, exists for human SNAPC4, the C. elegans genome encodes four homologs of human SNAPC1 (worm SNPC-1.1, -1.2, -1.3, and -1.5) and four homologs of human SNAPC3 (worm SNPC-3.1, -3.2, -3.3, and -3.4, Figure 1B; Li et alo, 2004). From our mass spectrometry analysis, six of the eight $C$. elegans homologs of SNAPC 1 and SNAPC3 co-purified with SNPC-4::3xFlag from both him-8(-) and fem-1(-) genetic backgrounds (Figure 1B,C). These results revealed that SNPC-4 interacts with both snRNA and piRNA transcriptional machinery.

\section{SNPC-1.3 interacts with the core piRNA biogenesis factor SNPC-4 during spermatogenesis}

We also identified proteins that co-purified with SNPC-4::3xFlag from him-8(-), but not fem-1(-) mutants. We were particularly interested in SNPC-1.3 because of its homology to the mammalian SNAPC1 subunit of the snRNA transcription complex. We confirmed that SNPC-1.3 interacts with SNPC-4 by using CRISPR/Cas9 genome editing to generate an endogenously tagged snpc-1.3::ollas strain. We then crossed snpc-1.3::ollas into the snpc-4::3xflag strain and performed immunoprecipitation with anti-Flag antibodies. In agreement with the mass spectrometry data, SNPC-4::3xFlag and SNPC-1.3:Ollas interacted robustly during spermatogenesis. The interaction was detectable at a much lower level during oogenesis (Figure 1D). The reciprocal co-immunoprecipitation of SNPC1.3::3xFlag followed by western blotting for SNPC-4::Ollas confirmed this biochemical interaction (Figure 1-figure supplement $1 \mathrm{H}$ ), suggesting that SNPC-1.3 forms a complex with the previously characterized piRNA biogenesis factor SNPC-4. 
A

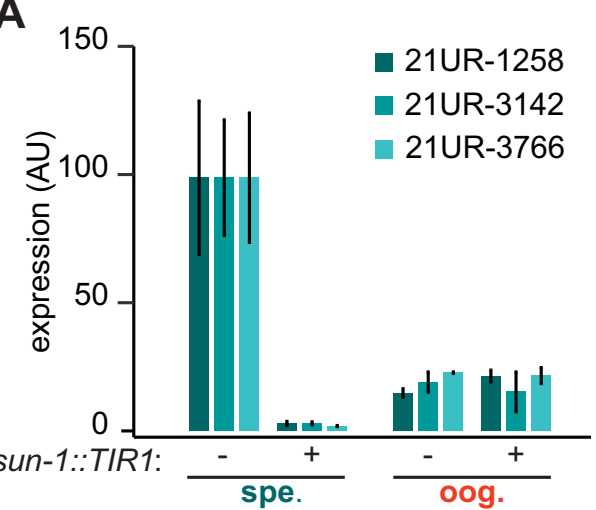

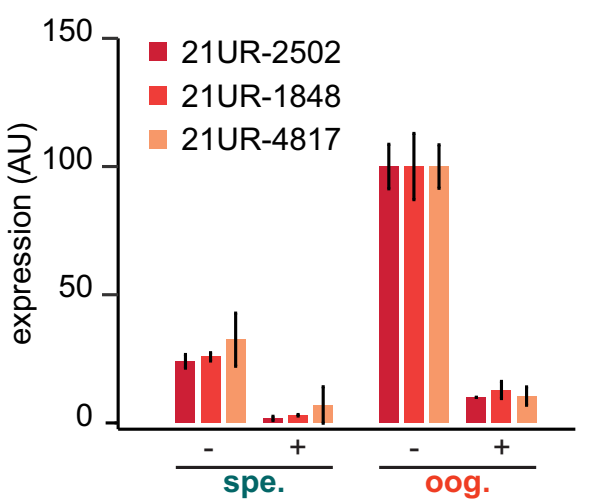

B

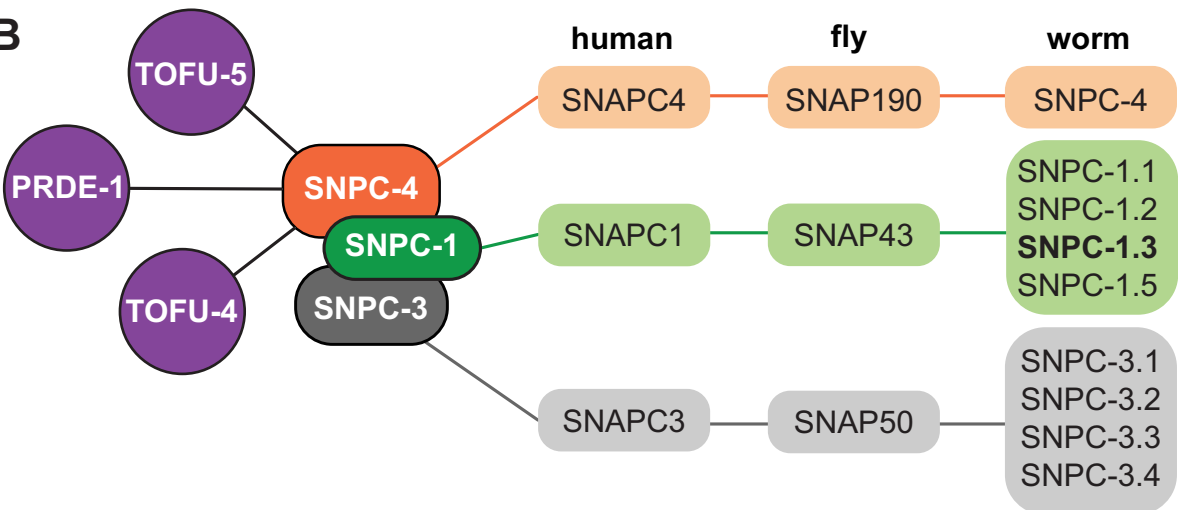

C

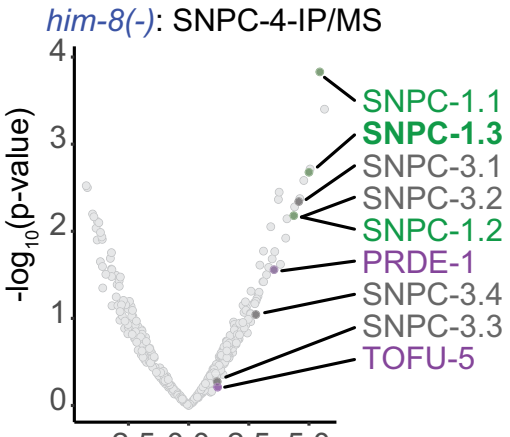

$-2.50 .02 .55 .0$

$\log _{2}($ mean of IP/control)

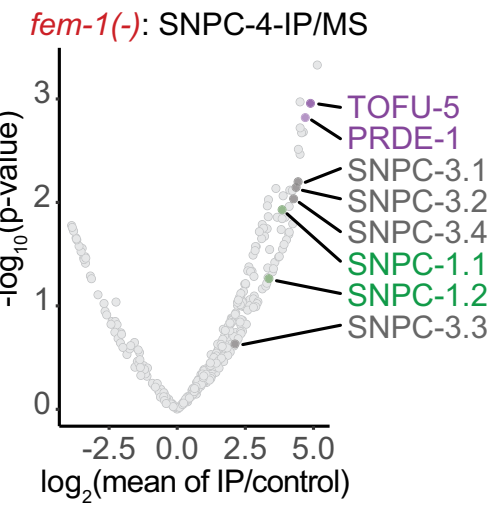

D

\begin{tabular}{|c|c|c|c|c|c|c|c|c|c|c|}
\hline \multirow[b]{2}{*}{ snpc-4::3xflag: } & \multicolumn{5}{|c|}{ Input } & \multicolumn{5}{|c|}{ IP: anti-Flag } \\
\hline & + & + & + & - & + & + & + & + & - & + \\
\hline snpc-1.3::ollas: & + & + & - & + & - & + & + & - & + & - \\
\hline prde-1::ollas: & - & - & - & - & + & - & - & - & - & + \\
\hline
\end{tabular}

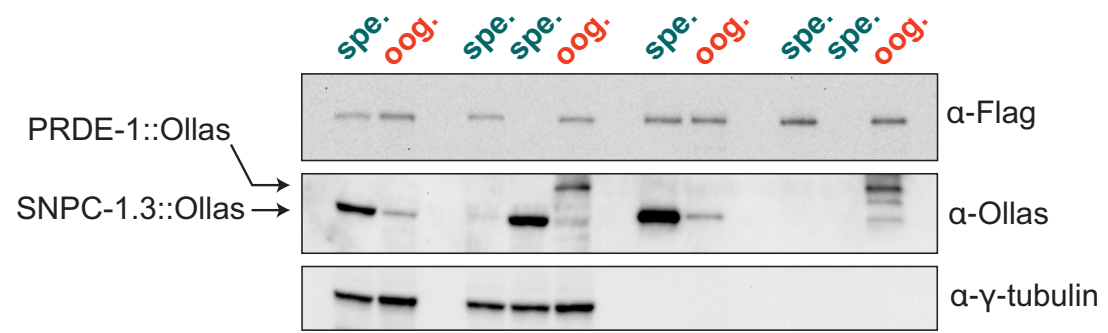

Figure 1. SNPC-4 and SNPC-1.3 are part of the male piRNA transcription complex. (A) SNPC-4 is required for both male and female piRNA expression. Taqman qPCR of male (left) and female (right) piRNAs normalized to U18 small nucleolar RNA in snpc-4::aid (denoted as '-') and snpc-4::aid; Psun-1:: TIR1 (denoted as ' +') worms. Both genotypes were placed on auxin, and collected during spermatogenesis (spe., $48 \mathrm{hr}$ ) and oogenesis (oog., $72 \mathrm{hr}$ ). Error bars: \pm SD from two technical replicates. (B) Schematic highlights the conservation of SNAPc homologs from C. elegans, D. melanogaster, and H. sapiens and catalogs all SNPC-4 (orange) interacting partners from previous work (Weick et al., 2014; Weng et al., 2019) or from our own analysis. Known piRNA biogenesis factors (purple), SNPC-1 paralogs (green), and SNPC-3 paralogs (gray) are indicated. (C) SNPC-1.3 interacts with SNPC-4 in only him-8(-) mutants. Volcano plots showing enrichment values of IP of SNPC-4 over control (control: him-8(-) mutants for top panel or fem-1(-) mutants for bottom panel) and analogous significance values for proteins that co-purified with SNPC-4::3xFlag from (top) him-8(-) mutants or (bottom) fem-1(-) mutants ( $n=2$ biological replicates). piRNA biogenesis factors (purple), SNPC-1 paralogs (green), and SNPC-3 paralogs (dark gray) are labeled in (B).

Figure 1 continued on next page 
Figure 1 continued

Although SNPC-3.1 and SNPC-3.2 are reported to have the same amino acid sequence, we have picked up differential peptide coverage in the fem-1(-) mutant for these two proteins and represented them as two different data points. (D) SNPC-4 interacts with SNPC-1.3. Anti-Flag immunoprecipitation of SNPC-4::3xFlag and western blot for SNPC-1.3::Ollas during spermatogenesis (spe.) and oogenesis (oog.). PRDE-1::Ollas was used as a positive control for interaction with SNPC-4::3xFlag (Kasper et al., 2014). $\gamma$-Tubulin was used as the loading control.

The online version of this article includes the following source data and figure supplement(s) for figure 1:

Source data 1. Source data for Figure 1A.

Figure supplement 1. Validation of strains and mass spectrometry.

\section{SNPC-1.3 is enriched in the male germline}

To determine whether SNPC-1.3 expression is restricted to the germline, we first examined snpc-1.3 mRNA levels during early spermatogenesis (36 hr post-L1 hatching) in worms fed glp-1 RNAi, which abrogates germline development. The mRNA of snpc-4, which is highly expressed in the germline (Kasper et al., 2014), was used as a control. Knockdown of glp-1 mRNA markedly reduced both snpc-1.3 and snpc-4 mRNAs. SNPC-1.3::3xFlag protein expression was also reduced in a glp-4 temperature-sensitive mutant, which fails to develop fully expanded germlines at $25^{\circ} \mathrm{C}$ (Beanan and Strome, 1992), suggesting that SNPC-1.3 is predominantly expressed in the germline (Figure 2A).

To examine differential snpc-1.3 expression between the sexes, we measured snpc-1.3 mRNA levels in him-8(-) males and fem-1(-) females. The expression of snpc-1.3 mRNA was greatly enriched in him-8(-) relative to fem-1(-), while snpc-4 mRNA did not show any differential expression. At the protein level, SNPC-1.3::3xFlag was also highly enriched in males as compared to females by western blotting (Figure 2B).

SNPC-4, along with other piRNA factors, such as PRDE-1, localize to one or two foci in each germline nuclei (Kasper et al., 2014; Weick et al., 2014; Weng et al., 2019). Given that SNPC-1.3 is present in a complex with SNPC-4 (Figure 1D), we hypothesized that SNPC-1.3 might show a similar localization pattern to these other piRNA factors. To examine the subcellular localization of SNPC-1.3, we performed immunofluorescence in snpc-4::3xflag; snpc-1.3::ollas adult males and hermaphrodites. In the male germline, SNPC-1.3::Ollas colocalized with SNPC-4::3xFlag in the same nuclear foci (Figure 2C). In contrast, no SNPC-1.3::Ollas signal was detected above background in hermaphrodites (Figure 2C). Taken together, these data indicate that SNPC-1.3 co-localizes with SNPC-4 specifically in the male germline.

\section{SNPC-1.3 is required for transcription of male piRNAs}

Given the prominent interaction between SNPC-1.3 and SNPC-4 in the male germline (Figure 1D), we hypothesized that SNPC-1.3 might be required for piRNA expression during spermatogenesis. To test this hypothesis, we generated a snpc-1.3 null allele by introducing mutations that result in a premature stop codon located eight amino acids away from the start codon at the snpc-1.3 locus. We examined spermatogenesis in hermaphrodites and him-8(-) males and examined oogenesis in adult hermaphrodites and fem-1(-) females. As a control, we analyzed the loss-of-function mutant of the $C$. elegans Piwi protein, prg-1(-), which almost completely lacked male and female piRNAs (Figure 3A), as expected. Levels of male piRNAs were dramatically reduced in snpc-1.3(-) hermaphrodites during spermatogenesis and in him-8(-); snpc-1.3(-) males, whereas female piRNAs were largely unaltered in snpc-1.3(-) adult hermaphrodites and in fem-1(-); snpc-1.3(-) females (Figure 3A,B). Unexpectedly, female piRNAs were also moderately upregulated by at least twofold in snpc-1.3(-) mutants undergoing spermatogenesis and in him-8(-); snpc-1.3(-) males. These findings suggest that, in addition to activating male piRNAs, SNPC-1.3 suppresses the expression of female piRNAs in the male germline, possibly by preferentially recruiting core factors such as SNPC-4 to male piRNA loci. As SNPC-4 is known to activate transcription of snRNAs as well as piRNAs (Kasper et al., 2014), we asked whether SNPC-1.3 is also required for transcribing snRNAs. To test this, we measured U1 snRNA levels in hermaphrodite adults after RNAi-mediated knockdown of snpc-1.3. In contrast to the reduction of U1 observed in snpc-4 RNAi, U1 levels were not significantly altered when snpc-1.3 was depleted (Figure 3-figure supplement 2A), suggesting that, unlike SNPC-4, SNPC-1.3 is likely specific to the transcription of male piR$\mathrm{NAs}$ and does not play a role in snRNA transcription. 

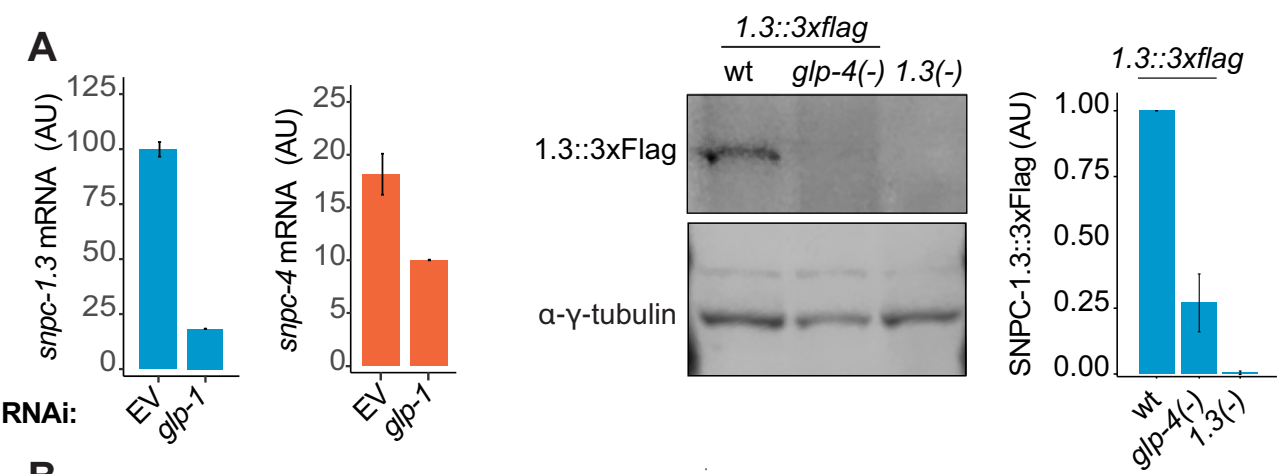

B
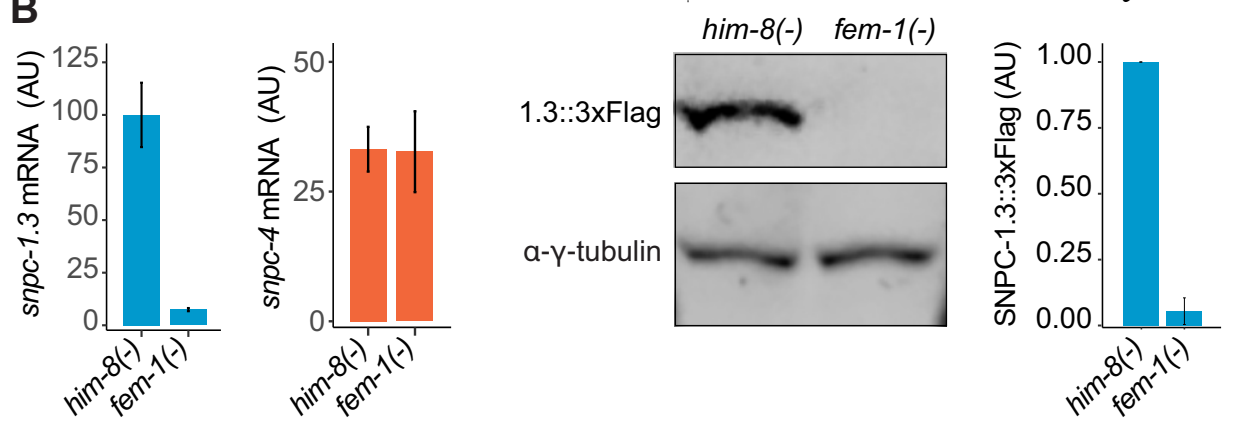

C
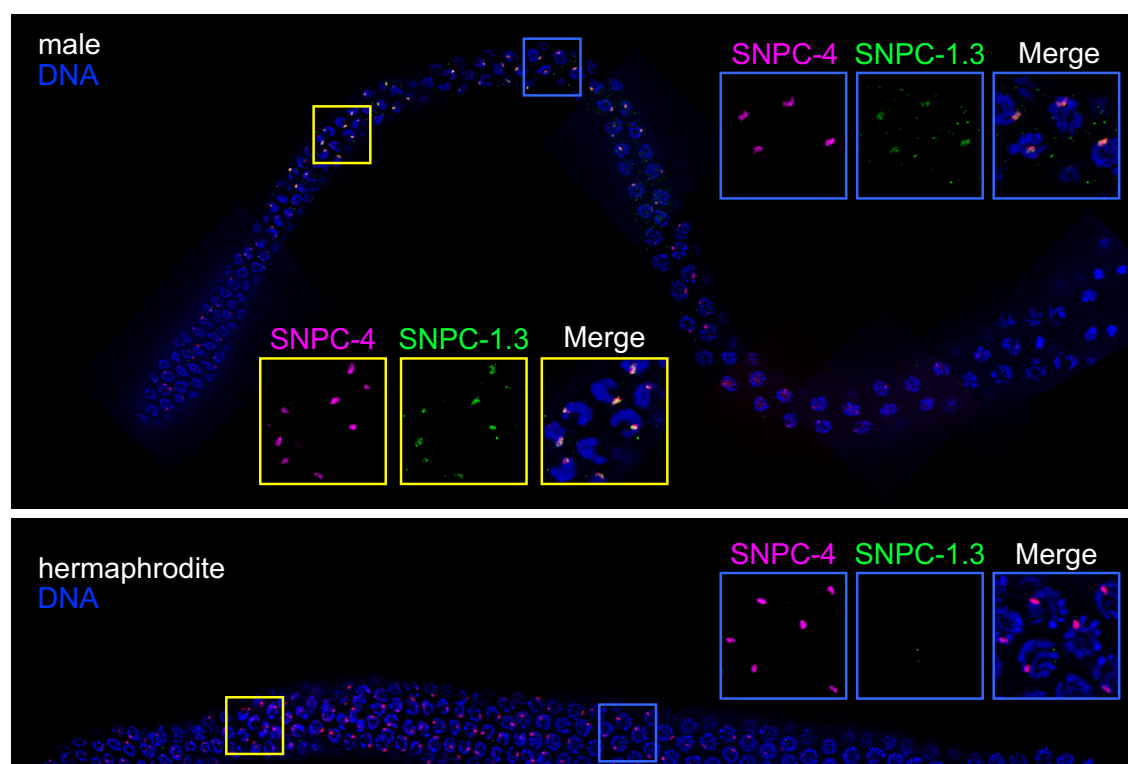

SNPC-4 SNPC-1.3 Merge
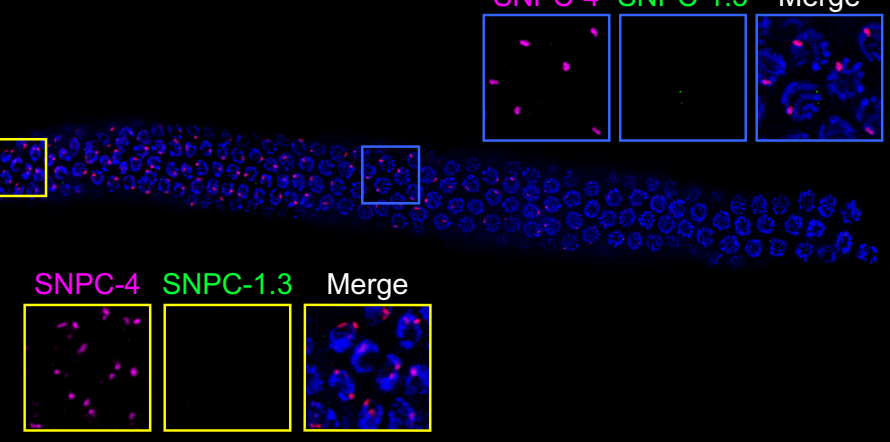

$25 \mu \mathrm{M}$

Figure 2. SNPC-1.3 is enriched in the male germline. (A) SNPC-1.3 is predominantly germline-expressed. (Left) snpc-1.3 mRNA expression is reduced upon RNAi-mediated knockdown of glp-1 during early spermatogenesis (36 hr). The housekeeping gene eft-2 was used for normalization. Error bars: \pm SD of two technical replicates. (Right) Western blot and quantification of SNPC-1.3::3xFlag in wild type, glp-4(-), and snpc-1.3(-) (no-Flag control) during spermatogenesis. Error bars: \pm SD of two biological replicates. $\gamma$-Tubulin was used as the loading control. (B) SNPC-1.3 is more highly expressed in Figure 2 continued on next page 
Figure 2 continued

males. (Left) snpc-1.3 mRNA expression is dramatically enriched in him-8(-) males over fem-1(-) females during spermatogenesis, whereas snpc-4 mRNA expression shows no specific enrichment. eft-2 was used for normalization. Error bars: \pm SD of two technical replicates. (Right) Western blot and quantification of SNPC-1.3::3xFlag in him-8(-) and fem-1(-). Error bars: \pm SD of two biological replicates. $\gamma$-Tubulin was used as the loading control. (C) SNPC-1.3 colocalizes with SNPC-4 in the male germline. Dissected adult male (top) and hermaphrodite (bottom) germlines stained for DNA, SNPC4::3xFlag (magenta) and SNPC-1.3::Ollas (green) in a N2 background. Yellow insets: transition zone. Blue insets: pachytene. Representative image of three biological replicates is shown (male, $n=21,18,15$ and hermaphrodite, $n=18,10,10$ ). Scale bar, $25 \mu \mathrm{m}$.

The online version of this article includes the following source data for figure 2 :

Source data 1. Source data for Figure 2A.

Source data 2. Source data for Figure 2A.

Source data 3. Source data for Figure 2B.

Source data 4. Source data for Figure 2B.

To extend these findings, we identified piRNAs enriched during spermatogenesis and oogenesis by small RNA-seq in wild-type worms. Using a 1.2-fold threshold and false discovery rate (FDR) of $\leq 0.05$, a total of 6,368 of 14,714 piRNAs on chromosome IV were differentially expressed (Figure 3C; Figure 3-figure supplements 1 and 2C; Supplementary file 1). Among these, 4,060 piRNAs were upregulated during spermatogenesis (hereafter referred to as male piRNAs) and 2,308 piRNAs were upregulated during oogenesis, which we define as female piRNAs. We compared this dataset with our previous study that identified and categorized spermatogenesis- and oogenesisenriched piRNAs, as well as piRNAs that were not statistically enriched (NE) either during oogenesis or spermatogenesis (Billi et al., 2013). Most male piRNAs identified in this study were also identified in our previous study (82\%; 3,316/4,060; Figure 3C). Next, we investigated how loss of snpc-1.3 affects global piRNA expression by performing small RNA-seq in wild type versus snpc-1.3(-) mutants during spermatogenesis. We identified 3,601 piRNAs that were downregulated in a snpc1.3(-) mutant compared to wild type (Figure 3D, Figure 3-figure supplement 2D, Supplementary file 2). Of these, 3,002 overlapped with spermatogenesis-enriched piRNAs identified in our previous study (Billi et al., 2013; Figure 3D). Additionally, 85\% $(3,452 / 4,060)$ of male piRNAs were depleted in snpc-1.3(-) mutants, suggesting that male piRNAs are regulated by SNPC-1.3 (Figure 3E, Figure 3-figure supplement 2E). Consistent with our Taqman analysis (Figure 3A,B), $73 \%(1,687 / 2,308)$ of oogenesis-enriched piRNAs identified in our study were significantly upregulated in snpc-1.3(-) mutants during spermatogenesis (Figure 3F).

We next analyzed the genomic loci of male piRNAs and snpc-1.3-dependent piRNAs. As expected, the intersection of these two piRNA subsets displayed strong enrichment for the eight nt core motif and the 5'-most position of this core motif was enriched for cytosine (CNGTTTCA. Figure 3E; Figure 3-figure supplement 2E). In contrast, the core motif found upstream of female piRNAs upregulated upon loss of snpc-1.3 displayed a much weaker bias for the $5^{\prime}$ cytosine (Figure 3F). These observations validate our previous findings that male and female core motifs are distinct (Billi et al., 2013). Taken together, these data indicate that SNPC-1.3 is required for male piRNA expression.

\section{SNPC-1.3 binds male piRNA loci in a SNPC-4-dependent manner}

Given that SNPC-1.3 interacts with SNPC-4 and is required for expression of male piRNAs, we hypothesized that SNPC-1.3 might bind male piRNA loci in association with SNPC-4. To test this, we performed ChIP-qPCR to investigate SNPC-1.3 occupancy at regions of high piRNA density within the two large piRNA clusters on chromosome IV; an intergenic region lacking piRNAs served as a control. To determine whether SNPC-1.3 binding was dependent on SNPC-4, we again used the auxin-inducible degradation system to deplete SNPC-4 in the snpc-1.3::3xflag strain for $4 \mathrm{hr}$ prior to our spermatogenesis time point. In the presence of SNPC-4 expression, SNPC-1.3 was enriched at both piRNA clusters, albeit to a lesser degree at the small cluster, and this enrichment was lost upon SNPC-4 depletion (Figure 4A, Figure 4-figure supplement 1A). These data indicate that SNPC1.3 binds piRNA loci during spermatogenesis in a SNPC-4-dependent manner in vivo.

To examine the genome-wide binding profile of SNPC-1.3 and its dependency on SNPC-4, we performed ChIP-seq of N2, snpc-1.3::3xflag, and snpc-1.3::3xflag; snpc-4::aid; Psun-1::TIR1 worms 


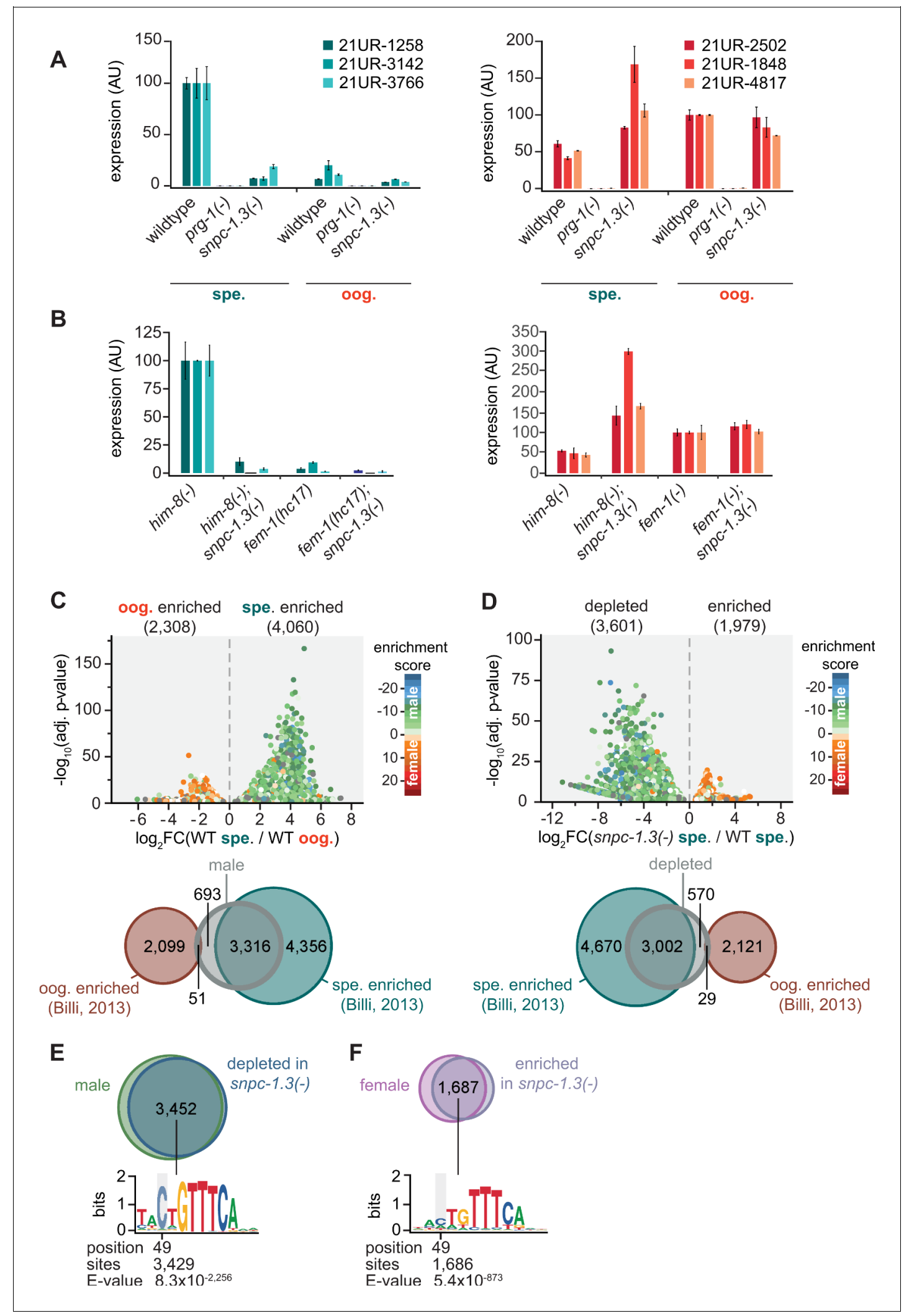

Figure 3. SNPC-1.3 is required for transcription of male piRNAs. (A) snpc-1.3 is required for male piRNA expression (spe.) but is dispensable for female piRNA expression during oogenesis (oog.). Taqman QPCR and quantification of representative male (left) and female (right) piRNAs at spermatogenic and oogenic time points normalized to U18. Error bars: \pm SD of two technical replicates. (B) him-8(-); snpc-1.3(-) mutant males exhibit severely impaired male piRNA expression and enhanced female piRNA expression. snpc-1.3 is not required for male or female piRNA expression in fem-1(-) females.

Figure 3 continued on next page 
Figure 3 continued

Error bars: \pm SD from two technical replicates. (C) piRNAs are differentially expressed during spermatogenesis (spe.) and oogenesis (oog.) in wild-type worms. (Top) Volcano plot showing piRNAs with $\geq 1.2$ fold-change and FDR of $\leq 0.05 \mathrm{in} 48 \mathrm{hr}$ (spe.) versus $72 \mathrm{hr}$ (oog.). piRNAs are colored according to male and female enrichment scores from Billi et al., 2013. (Bottom) Overlap of male piRNAs (spe.) in wild type at 48 hr with spermatogenesis-enriched and oogenesis-enriched piRNAs defined in Billi et al., 2013. (D) piRNAs depleted in snpc-1.3(-) comprise mostly of male piRNAs. (Top) Volcano plot shows piRNAs with $\geq 1.2$ fold-change and FDR $\leq 0.05$ in snpc-1.3(-) mutant versus wild type during spermatogenesis (spe.). piRNAs are colored according to male and female enrichment scores from Billi et alo, 2013. (Bottom) Overlap of snpc-1.3-dependent piRNAs with spermatogenesis- and oogenesis-enriched piRNAs defined in Billi et al., 2013. (E) Male piRNAs that are depleted in snpc-1.3(-) have a conserved upstream motif with a strong $5^{\prime} \mathrm{C}$ bias. (Top) Overlap of snpc-1.3-dependent piRNAs with male piRNAs shown in (C). (Bottom) Logo plot displays conserved motif upstream of each piRNA. Median position of the C-nucleotide of the identified motif, number of piRNAs, and associated E-value are listed. (F) Female piRNAs are upregulated in snpc-1.3(-) mutants during spermatogenesis. (Top) Overlap of piRNAs upregulated at $72 \mathrm{hr}$ (oog.) with piRNAs enriched in snpc-1.3() at $48 \mathrm{hr}$ (spe.). (Bottom) Logo plot displays conserved motif upstream of each piRNA. Median position of the C-nucleotide of the identified motif, number of piRNAs, and associated E-value are listed.

The online version of this article includes the following source data and figure supplement(s) for figure 3 :

Source data 1. Source data for Figure 3A.

Source data 2. Source data for Figure 3B.

Figure supplement 1. Small RNA-seq analysis pipeline.

Figure supplement 2. Quality control of small RNA-seq and validation analysis.

during spermatogenesis (Figure 4-figure supplement 1B,C). Consistent with our ChIP-qPCR results, SNPC-1.3 binds piRNA clusters in a SNPC-4-dependent manner (Figure 4B, Figure 4-figure supplement 1D). By quantifying the SNPC-1.3 signal over consecutive, non-overlapping $1 \mathrm{~kb}$ bins across the entire genome, we identified $6911 \mathrm{~kb}$ regions within the chromosome IV piRNA clusters that were enriched for SNPC-1.3 in snpc-1.3::3xflag compared to N2 (Figure 4C, Figure 4-figure supplement 1G). Relative to snpc-1.3::3xflag, worms depleted of SNPC-4 showed loss of SNPC1.3 in $7491 \mathrm{~kb}$ regions on chromosome IV piRNA clusters (Figure 4D, Figure 4-figure supplement 1F). Furthermore, SNPC-1.3 enrichment $\left(p<2.2 \times 10^{-16}\right)$ and depletion $\left(p<2.2 \times 10^{-16}\right)$ were specific to the piRNA clusters on chromosome IV, and more than half (393/691) of the SNPC-1.3-enriched regions in snpc-1.3::3xflag worms were depleted upon degradation of SNPC-4 (Figure 4C,D, Figure 4-figure supplement 1F,G).

To determine whether SNPC-1.3 preferentially binds male piRNA loci, we characterized the SNPC-1.3 signal around individual $5^{\prime}$ nucleotides of mature piRNAs. Again, we classified piRNAs as male, female, or not significantly enriched (NE) in either sex, based on our small RNA-seq analysis in wild-type hermaphrodites during spermatogenesis and oogenesis (Figure 3C). SNPC-1.3 binding at male piRNA loci was most enriched just upstream of the piRNA $5^{\prime}$ nucleotide, which overlaps the conserved core motif (Figure 4E, Figure 4-figure supplement 1E). This binding profile was very distinct for $1 \mathrm{~kb}$ bins that contained only male piRNAs (Figure 4F, Figure 4-figure supplement $1 \mathrm{H}$ ). Upon depletion of SNPC-4, this peak in male piRNAs was lost (Figure 4E, Figure 4-figure supplement 1E). Although the binding profiles for individual female piRNAs exhibited more variability, there was little evidence for SNPC-1.3 binding and dependency on SNPC-4 at female loci (Figure 4E, Figure 4-figure supplement 1E). Compared to the binding profile in male piRNA loci, SNPC-1.3 binding was observed to a lesser extent in non-enriched piRNAs (Figure 4E, Figure 4figure supplement 1E). Taken together, these observations indicate that SNPC-1.3 requires the core piRNA factor SNPC-4 to bind the piRNA clusters during spermatogenesis.

\section{TRA-1 represses snpc-1.3 and male piRNA expression during oogenesis}

As male piRNA expression and SNPC-1.3 protein expression are largely restricted to the male germline, we asked how snpc-1.3 mRNA expression is regulated across development. C. elegans hermaphrodites produce sperm during the L4 stage and transition to producing oocytes as adults. To understand the mRNA expression profile of snpc-1.3 relative to snpc-4 and other developmentally regulated genes, we performed qRT-PCR across hermaphrodite development. snpc-4 mRNA is expressed at low levels during spermatogenesis, but dramatically increases during oogenesis (Figures 5A and 1D; Figure 1-figure supplement 1H). These data suggest that low levels of SNPC-4 are sufficient for activating male piRNA biogenesis during spermatogenesis. Consistent with SNPC-1.3 protein expression (Figure 1D), snpc-1.3 mRNA levels peak in L3 to early L4 stages, 
A
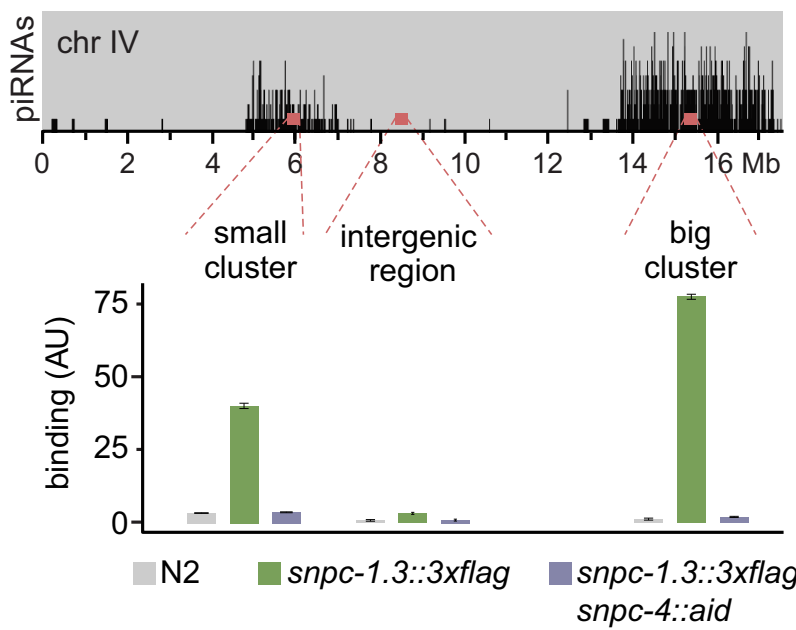

C

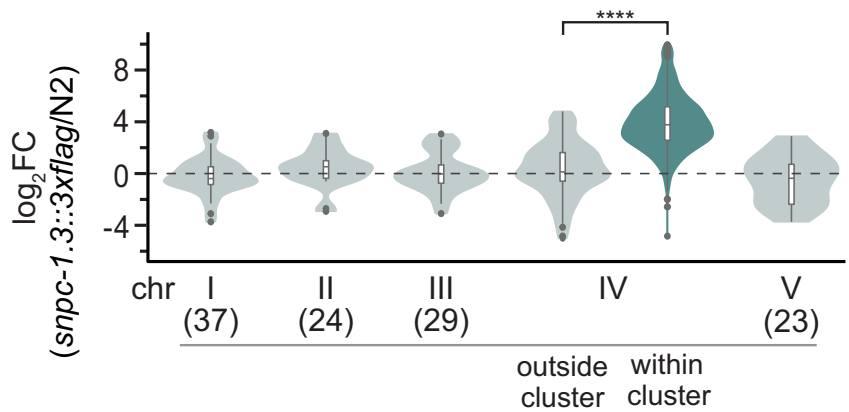

(93) (691)

E

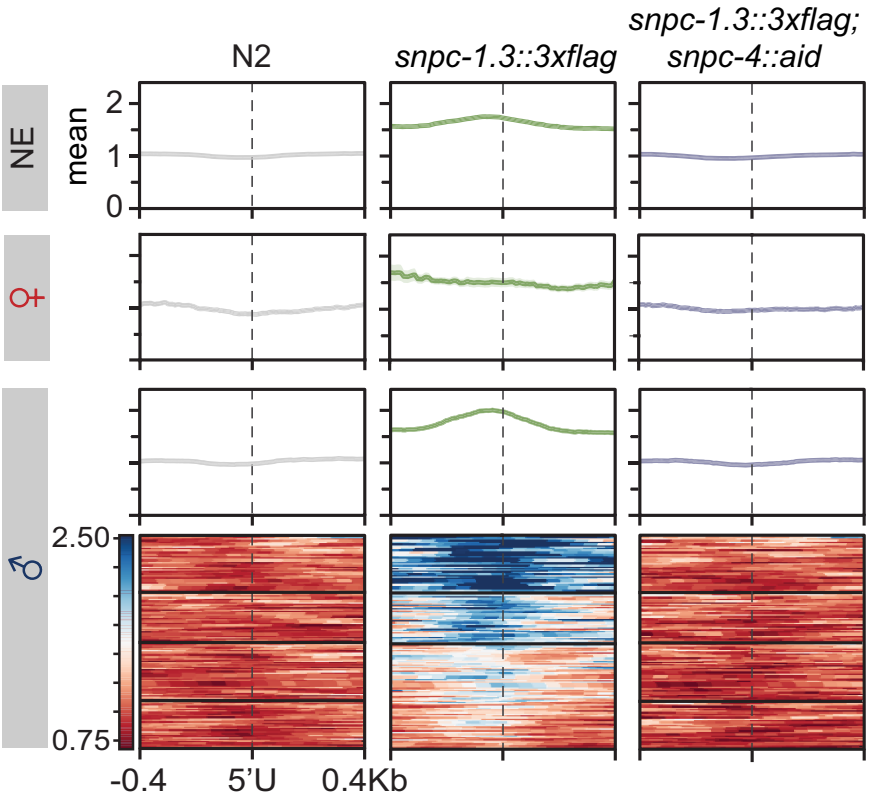

B
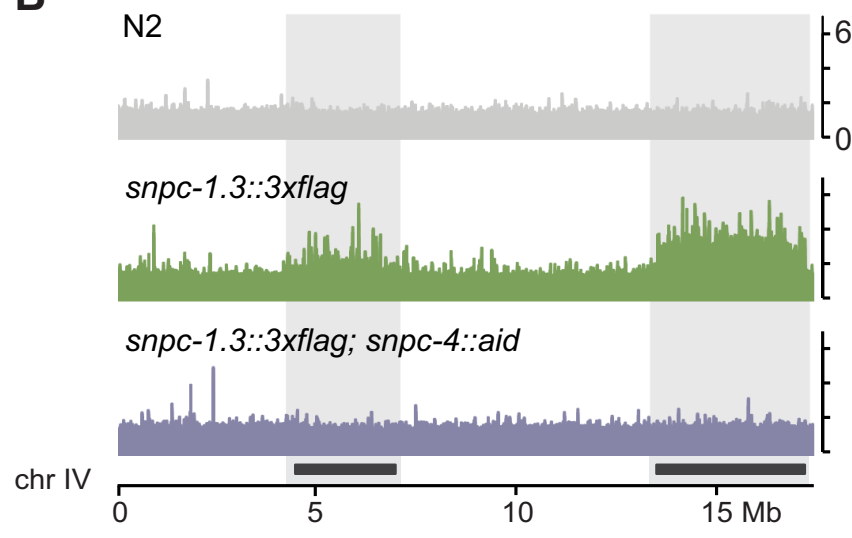

D

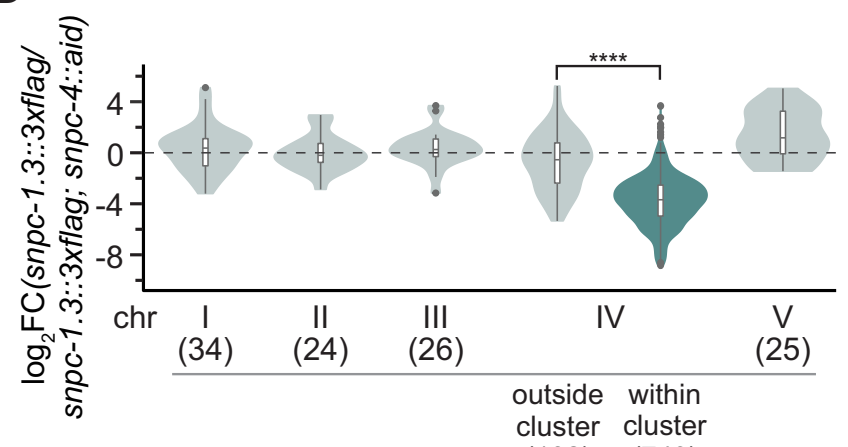

(102) (749)

$\mathbf{F}$

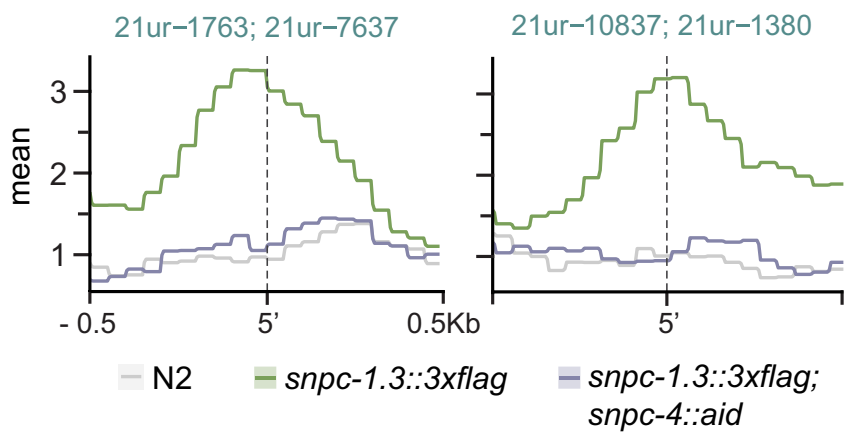

Figure 4. SNPC-1.3 binds male piRNA loci in a SNPC-4-dependent manner. (A) SNPC-1.3 binding at the piRNA clusters requires SNPC-4. SNPC1.3::3xFlag binding normalized to input (mean \pm SD of two technical replicates) on chromosome IV by ChIP-qPCR in N2, snpc-1.3::3xflag, and snpc1.3::3xflag; snpc-4::aid::ollas, which undergoes TIR-1-mediated degradation by addition of auxin (snpc-4::aid). Top panel depicts the density of piRNAs on chromosome IV with piRNAs predominantly found in the small (4.5-7 Mb) and big (13.5-17.2 Mb) clusters. (B) SNPC-1.3 binding profiles across chromosome IV in N2, snpc-1.3::3xflag, and snpc-1.3::3xflag; snpc-4::aid. The locations of the two piRNAs clusters are highlighted. (C) SNPC-1.3 binding Figure 4 continued on next page 
Figure 4 continued

is enriched at piRNA clusters on chromosome IV. SNPC-1.3-bound regions are enriched within piRNA clusters compared to regions outside of the piRNA clusters on chromosome IV ( ${ }^{\star \star \star \star} p \leq 0.0001$, Wilcoxon rank sum test). The number of bins analyzed is listed in parentheses. (D) SNPC-1.3 enrichment at piRNA clusters is dependent on SNPC-4. SNPC-1.3-bound regions within piRNA clusters are depleted compared to regions outside of the piRNA clusters on chromosome IV upon loss of SNPC-4 $\left(^{\star * * *} p \leq 0.0001\right.$, Wilcoxon rank sum test). The number of bins analyzed is listed in parentheses. (E) Distribution of SNPC-1.3 reads (mean density \pm standard error) around the $5^{\prime}$ nucleotide of mature piRNAs at the piRNA clusters. To resolve SNPC-1.3 binding between male and female piRNAs despite the high density of piRNAs, we selected $1 \mathrm{~kb}$ bins with all male (100), female (19), or non-enriched (279) piRNAs. Heat maps represent ChIP signal in $1 \mathrm{~kb}$ bins around the $5^{\prime}$ nucleotide of all 100 mature male piRNAs, ranked according to SNPC-1.3 signal. (F) Examples of SNPC-1.3 binding at two regions containing two male piRNA loci. Regions are anchored on the $5^{\prime}$ nucleotide of each mature male piRNA and show mean read density \pm standard error.

The online version of this article includes the following source data and figure supplement(s) for figure 4:

Source data 1. Source data for Figure 4A.

Figure supplement 1. SNPC-1.3 ChIP-seq pipeline and quality control and biological replicates for SNPC-1.3 ChIP.

during spermatogenesis (Figure 5A). Given that snpc-1.3 expression across development is regulated at the mRNA level, we examined the sequences upstream of the snpc-1.3 coding region to identify potential cis-regulatory motifs. Less than $200 \mathrm{bp}$ upstream of the snpc-1.3 start codon, we identified three consensus binding sites for TRA-1 (Figure 5B), a transcription factor that controls the transition from spermatogenesis to oogenesis (Berkseth et al., 2013; Clarke and Berg, 1998; Zarkower and Hodgkin, 1993).

In the germline, TRA-1, a Gli family zinc-finger transcription factor, controls the sperm-to-oocyte decision by repressing both fog-1 and fog-3, which are required for controlling sexual cell fate (Berkseth et al., 2013; Chen and Ellis, 2000; Lamont and Kimble, 2007; Zarkower and Hodgkin, 1993). Loss-of-function tra-1 hermaphrodites exhibit masculinization of the female germline and develop phenotypically male-like traits (Hodgkin, 1987). We used RNAi to knock down tra-1 and observed significant ectopic upregulation of snpc-1.3 mRNA during oogenesis (Figure 5C). However, this upregulation of snpc-1.3 expression could be an indirect effect of masculinization of the germline. Therefore, to test whether TRA-1 directly regulates snpc-1.3, we generated strains harboring mutations at the three TRA-1 binding sites ( $t b s)$ in the endogenous snpc-1.3 promoter. Specifically, we mutated one (1xtbs), two (2xtbs), or all three (3xtbs) consensus TRA-1 binding motifs (Figure 5B). Disruption of the TRA-1 binding sites led to reduced TRA-1::3xFlag binding upstream of snpc-1.3 as revealed by ChIP-seq, with the 3xtbs mutant showing the greatest reduction of binding (Figure 5B, Figure 5-figure supplement 1D). In addition, snpc-1.3 mRNA levels were highly upregulated when multiple TRA-1 binding sites were mutagenized (Figure 5C), consistent with TRA1 directly repressing snpc-1.3 transcription during oogenesis. To confirm that SNPC-1.3 protein expression was also elevated in TRA-1 binding site mutants, we used CRISPR/Cas9 engineering to add a C-terminal 3xFlag tag at the snpc-1.3 locus in snpc-1.3 (2xtbs) mutants. Indeed, SNPC1.3::3xFlag showed increased expression in the snpc-1.3::3xFlag(2xtbs) mutant during spermatogenesis and especially oogenesis (Figure 5C). Taken together, these findings demonstrate TRA-1 binds to the snpc-1.3 promoter to repress its transcription during oogenesis.

Given that snpc-1.3 is robustly de-repressed during oogenesis in TRA-1 binding site mutants, we hypothesized that male piRNAs would also be ectopically upregulated during oogenesis. To test this, we performed small RNA-seq and compared piRNA levels in wild-type and snpc-1.3 (2xtbs) worms during oogenesis (Supplementary file 3). Using a 1.2-fold threshold and FDR of $\leq 0.05$, we observed 1,370 piRNAs in snpc-1.3 (2xtbs) mutants that were upregulated compared to wild type (Figure 5D). The majority of these upregulated piRNAs overlap with the male piRNAs that we identified in wild-type hermaphrodites (Figure 5D). We also confirmed this result by Taqman qPCR analysis, which showed that male piRNAs were significantly upregulated in snpc-1.3 (2xtbs) and snpc-1.3 (3xtbs) mutants compared to wild type during oogenesis (Figure 5E). Taken together, these data suggest that TRA-1 directly binds to tbs sites in the snpc-1.3 promoter to repress its transcription and consequently, male piRNA expression during oogenesis.

Our data showed that female piRNAs are inappropriately upregulated during spermatogenesis upon loss of snpc-1.3 (Figure 3A). Consistent with this result, female piRNAs show reduced expression during oogenesis upon upregulation of SNPC-1.3 expression in snpc-1.3 (2xtbs) and snpc-1.3 (3xtbs) mutants compared to wild type (Figure 5E). We posit that SNPC-1.3 plays a direct role in 
A

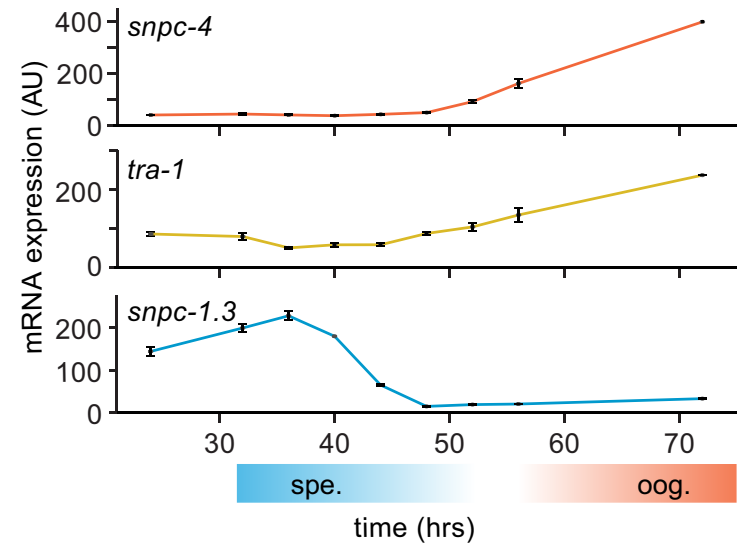

C

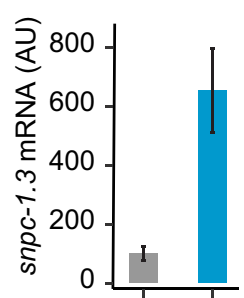

RNAi: EV tra-1
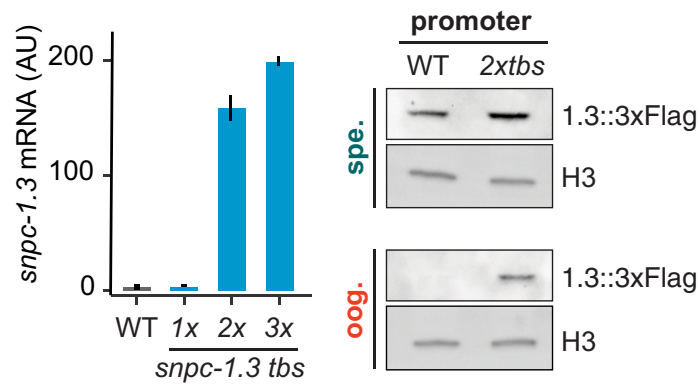

D
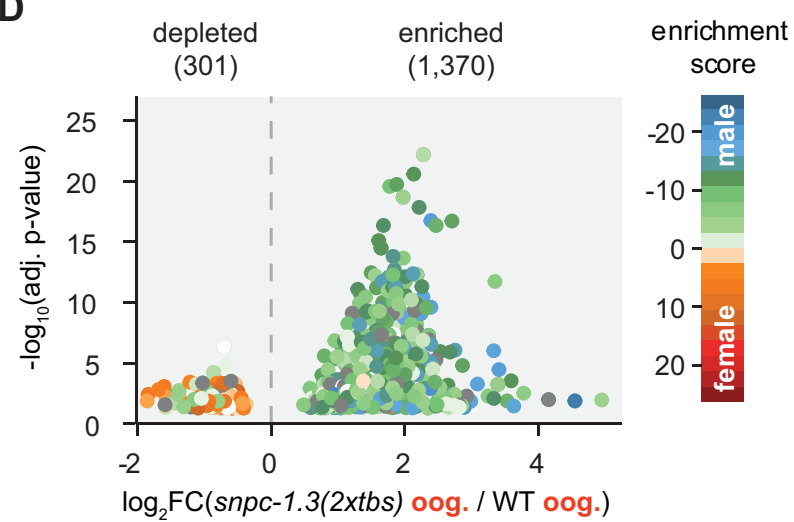

$\log _{2} \mathrm{FC}($ snpc-1.3(2xtbs) oog. / WT oog.)

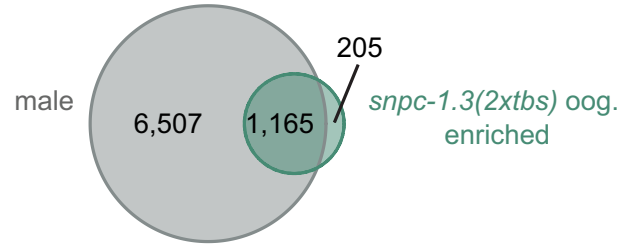

B wildtype

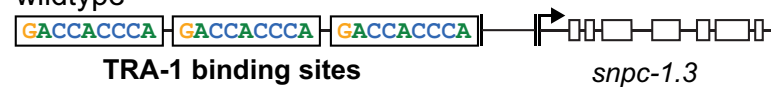

snpc-1.3(1xtbs)

GACCACCCA GACCACCA GACCAATGA

snpc-1.3(2xtbs)

GACCAATGA GACCAATGA GACCACCCA

snpc-1.3(3xtbs)
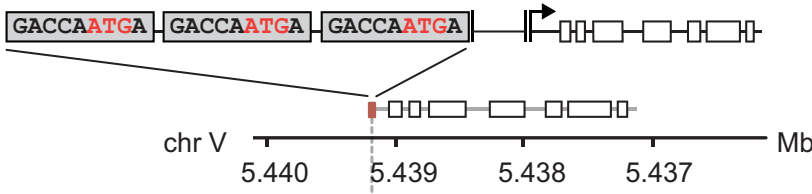

3xFlag::TRA-1 ChIP

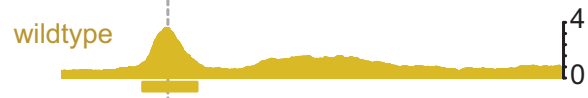

snpc-1.3(1xtbs)

snpc-1.3(2xtps)

snpc-1.3(3xtbs)

no-tag contrọl

E

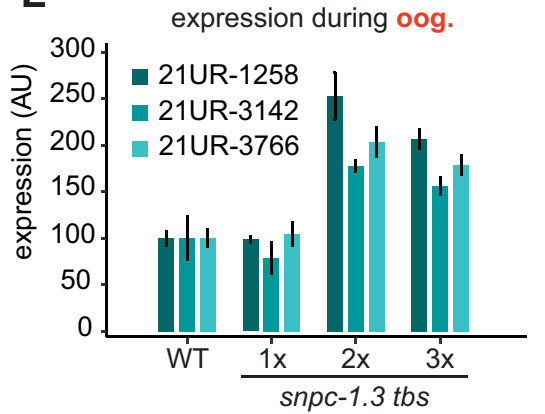

expression during oog.

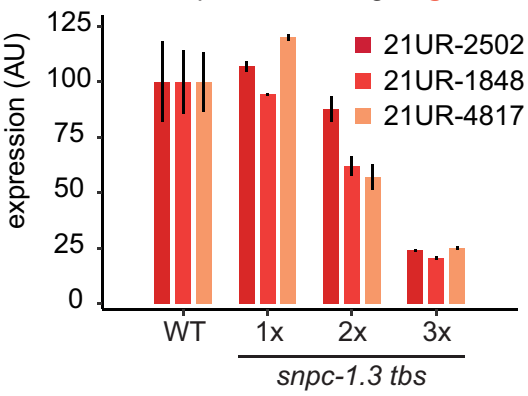

Figure 5. TRA-1 represses snpc-1.3 and male piRNAs expression during oogenesis. (A) snpc-1.3 mRNA levels peak during early spermatogenesis (spe.) while tra-1 mRNA levels are highest during oogenesis (oog.). qRT-PCR and quantification of snpc-1.3, snpc-4, and tra-1 mRNA normalized to eft-2 mRNA across hermaphrodite development. Time zero corresponds to the time when synchronized L1s were plated. Error bars: \pm SD of two technical replicates. (B) TRA-1 binds to the snpc-1.3 promoter. Schematic of the three TRA-1 binding sites upstream of the snpc-1.3 locus in wild type (top). SiteFigure 5 continued on next page 
Figure 5 continued

specific mutations shown in red were made in one, two, or three of the TRA-1 binding sites (gray denotes the mutated motifs). (Bottom) TRA-1 binding is reduced in TRA-1 binding site mutants assayed by TRA-1 ChIP-seq. (C) TRA-1 represses snpc-1.3 mRNA expression during oogenesis. (Left) snpc-1.3 mRNA expression is drastically upregulated upon RNAi-mediated knockdown of tra-1 and (middle) in strains bearing mutations in two (2xtbs) or three (3xtbs) TRA-1 binding sites. Error bars indicate \pm SD from two technical replicates. (Right) Western blot of SNCP-1.3::3xFlag expression driven under the wild-type and 2xtbs mutant promoter during spermatogenesis (spe.) (top) and oogenesis (oog.) (bottom). H3 was used as the loading control. (D) A subset of male piRNAs are ectopically expressed during oogenesis in snpc-1.3 (2xtbs) mutants. (Top) Volcano plot showing differential piRNA expression between snpc-1.3 (2xtbs) mutants versus wild type during oogenesis (oog.). piRNAs are colored by enrichment scores from Billi et al., 2013. (Bottom) Overlap of male piRNAs defined in Figure 3C with upregulated piRNAs in snpc-1.3 (2xtbs) mutants. (E) Mutations at two (2xtbs) or three (3xtbs) TRA-1 binding sites enhance male piRNA expression (top) but attenuate female piRNA expression (bottom) during oogenesis. Error bars indicate \pm SD from two technical replicates.

The online version of this article includes the following source data and figure supplement(s) for figure 5:

Source data 1. Source data for Figure 5A.

Source data 2. Source data for Figure 5C,E.

Figure supplement 1. TRA-1 regulation of snpc-1.3 across hermaphrodite development.

activating male piRNA transcription, while indirectly limiting female piRNA transcription by sequestering core piRNA transcription factors to male piRNA loci.

\section{SNPC-1.3 is critical for male fertility}

Given the global depletion of male piRNAs in snpc-1.3(-) mutants and the progressive fertility defects seen in prg-1(-) mutants (Batista et al., 2008; Wang and Reinke, 2008), we hypothesized that snpc-1.3(-) worms might also show fertility defects. Indeed, snpc-1.3(-) hermaphrodites exhibited significantly reduced fertility compared to wild type when grown at $25^{\circ} \mathrm{C}$ (Figure $6 \mathrm{~A}$ ). To address whether this decreased fertility was due to defects during spermatogenesis or oogenesis, we compared brood sizes from crosses of fem-1(-) females and him-8(-) males with or without snpc1.3. Compared to him-8(-) males, him-8(-); snpc-1.3(-) males generated significantly smaller brood sizes when crossed with fem-1(-) females; in contrast, fem-1(-); snpc-1.3(-) and fem-1(-) females generated similar brood sizes when crossed with him-8(-) males (Figure 6B). As an orthogonal test, we crossed hermaphrodites to transgenic males expressing a fluorescent marker to facilitate counting of cross progeny. These transgenic males encode a reporter gene, Pcol-19::gfp, which drives GFP expression in the cuticle (Figure 6-figure supplement 1A). All Pcol-19::gfp; snpc-1.3(-) males produced fewer GFP+ progeny than wild-type Pcol-19::gfp males, whereas wild-type or snpc-1.3(-) hermaphrodites generated similar numbers of GFP+ progeny when crossed with wild-type Pcol-19::gfp males (Figure 6-figure supplement 1A). These results suggest that the reduced fertility of snpc1.3(-) mutants likely reflect defects during spermatogenesis.

To investigate the cause of snpc-1.3-dependent loss of male fertility, we examined spermiogenesis and sperm morphology in snpc-1.3(-) males. After meiotic differentiation in the male germline, male spermatids are induced by ejaculation and undergo spermiogenesis, a process that converts immature spermatids to motile sperm with a functioning pseudopod. Spermiogenesis can be induced in vitro by isolating spermatids directly from males and treating them with pronase (Shakes and Ward, 1989). Males lacking prg-1 still generate differentiated spermatids, but rarely produce normal pseudopodia upon activation (Figure 6C,D; Wang and Reinke, 2008). Similar to prg-1(-) mutants, snpc-1.3(-) spermatids were rarely able to form normal pseudopodia. In contrast, snpc-1.3 (3xtbs) sperm formed normal pseudopodia at a frequency similar to wild type (Figure 6C, D). In addition, many of the snpc-1.3(-) spermatids resembled sperm undergoing intermediate stages of spermiogenesis. Spermiogenesis, in vivo, starts off with spherical spermatids that enter into an intermediate stage characterized by the growth of spiky protrusions. This stage is then followed by fusion of the spiky protrusions into a motile pseudopod (Figure 6E). To understand the dynamics of snpc-1.3(-) sperm progression through spermiogenesis, we treated spermatids with pronase and observed each activated spermatid over time. Wild-type spermatids spent an average of $6.2 \mathrm{~min} \pm 4.5 \mathrm{~min}$ in the intermediate state before polarization and pseudopod development. In contrast, snpc-1.3(-) spermatids occupied the intermediate state for a significantly shorter period of time (2.9 $\mathrm{min} \pm 3.7 \mathrm{~min}, \mathrm{p}<0.05$; Student's t-test) before forming pseudopods. By tracking each individual spermatid across spermiogenesis, we found most snpc-1.3(-) spermatids were unable to sustain 
A

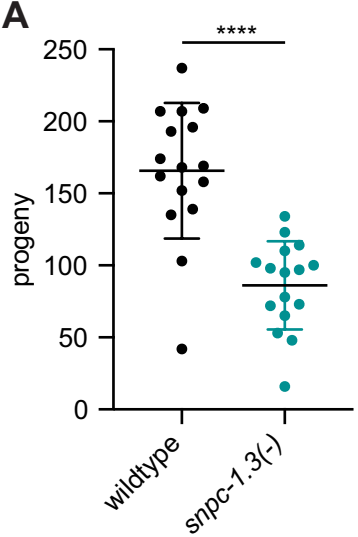

C
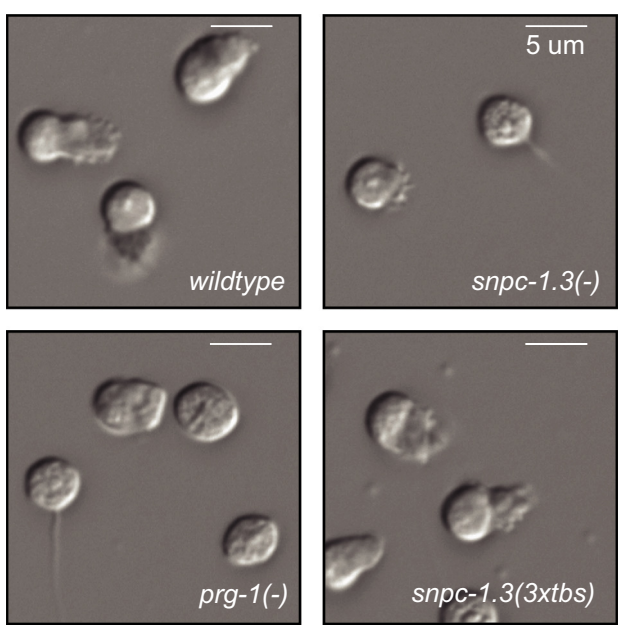

B

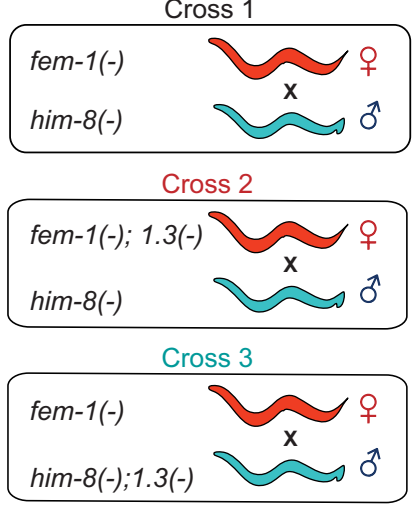

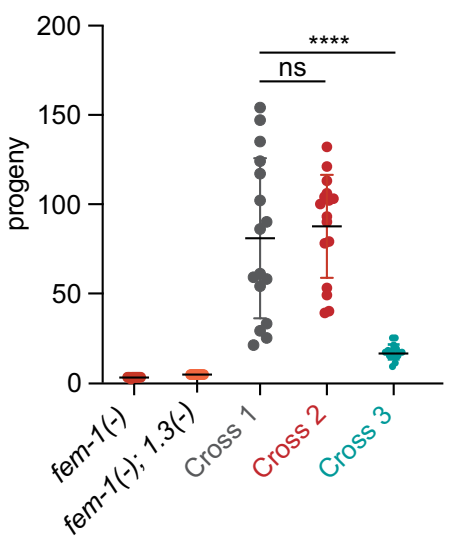

D

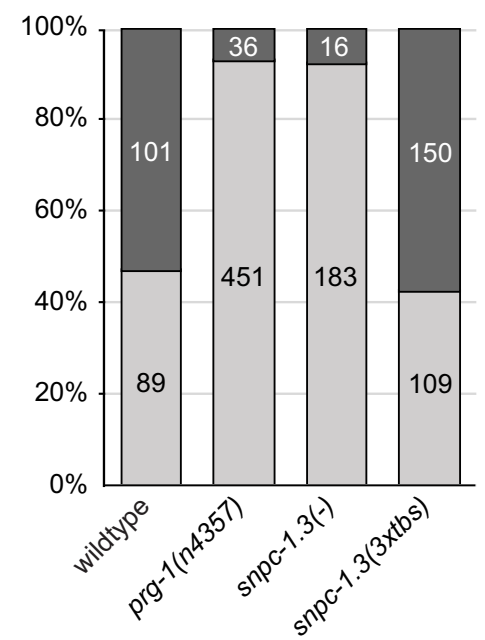

wild-type:

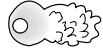

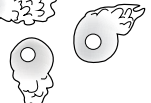

irregular/

no-pseudopod:

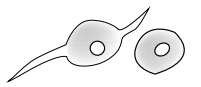

(0)

E
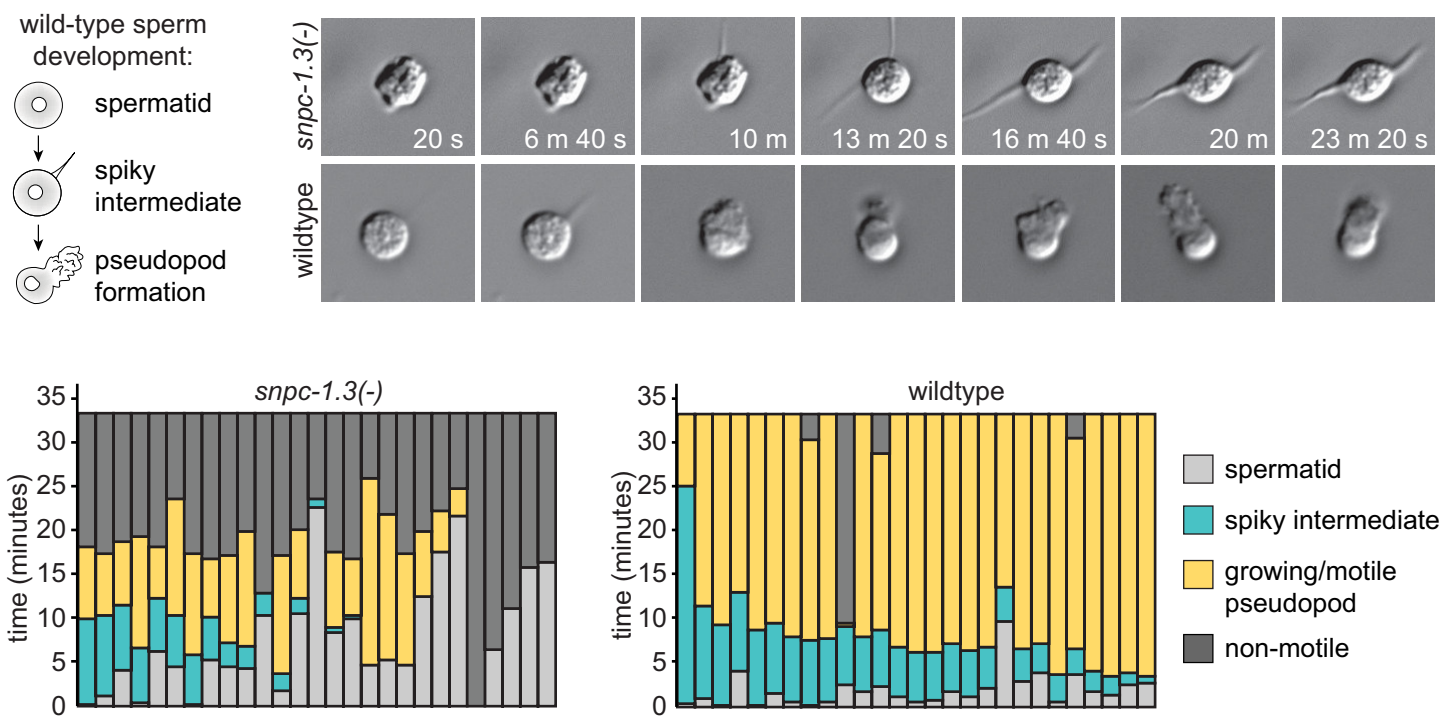

Figure 6. SNPC-1.3 is critical for male fertility. (A) snpc-1.3(-) hermaphrodites exhibit sterility at $25^{\circ} \mathrm{C}$. Circles correspond to the number of viable

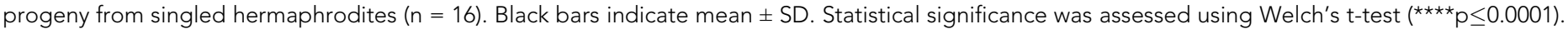
(B) snpc-1.3 promotes male fertility but is dispensable for female fertility. (Left) Diagram illustrates crosses between strains for mating assays (1.3(-) denotes snpc-1.3(-)). (Right) snpc-1.3(-); him-8(-) males crossed to fem-1(-) females show severe fertility defects (Cross 3). snpc-1.3; fem-1(-) females Figure 6 continued on next page 
Figure 6 continued

crossed to him-8(-) males (Cross 2) show equivalent fertility similar to fem-1(-) females crossed to him-8(-) males (Cross 1$)$. Circles correspond to the number of viable progeny from cross $(n=16)$. Black bars indicate mean \pm SD. Statistical significance was assessed using Welch's t-test (ns: not significant; $\left.{ }^{* \star \star *} p \leq 0.0001\right)$. (C) snpc-1.3(-) spermatids exhibit severe morphological defects. Images of pronase-treated sperm of wild-type, prg-1(-), snpc-1.3(-), and snpc-1.3 (2xtbs) males. (D) snpc-1.3(-) spermatids exhibit severe sperm maturation defects. (E) (Top) Images depicted at 3 min intervals of a sperm undergoing activation and maturation. Imaging of spermatid commenced $\sim 3$ min after pronase treatment. (Bottom) Graphical display of individual sperm tracked over time after pronase treatment.

The online version of this article includes the following source data and figure supplement(s) for figure 6:

Source data 1. Source data for Figure 6A.

Source data 2. Source data for Figure 6B.

Source data 3. Source data for Figure 6E.

Figure supplement 1. SNPC-1.3 is critical for male fertility.

pseudopod growth. While wild-type spermatids exhibited pseudopod growth and motility for an average of $24 \mathrm{~min} \pm 10.35 \mathrm{~min}$, snpc-1.3(-) spermatids sustained growth for a significantly shorter period of time ( $7.3 \mathrm{~min} \pm 5.7 \mathrm{~min}, \mathrm{p}<0.05$; Student's t-test) before becoming immotile (Figure 6E). These results indicate that spnc-1.3(-) males have defective spermatogenesis processes and exhibit similar fertility defects as prg-1(-) mutants.

\section{Discussion}

Our data indicate that $C$. elegans SNPC-1.3, a human SNAPC1 ortholog, functions as a male piRNA transcription factor. SNPC-1.3 interacts with SNPC-4 in foci in male germ cell nuclei (Figure 2) and, by preferentially binding male piRNA promoters (Figure 4), is critical for their expression (Figure 3). SNPC-1.3 expression, reflecting the developmental profile of male piRNAs (Figure 5-figure supplement 1A), is highest during spermatogenesis. We demonstrate that the snpc-1.3 locus itself is regulated by the sex determination regulator, TRA-1 (Figure 5). During spermatogenesis, tra-1 expression is low, and snpc-1.3 and other male-promoting genes are licensed for expression. In contrast, tra-1 expression is upregulated during oogenesis and TRA-1 binds the snpc-1.3 promoter to repress its transcription, leading to the expression of female over male piRNAs (Figure 7). We propose that SNPC-1.3, via its interaction with SNPC-4, can direct the specificity of the core piRNA complex preferentially to male piRNA loci.

\section{How is the expression of male and female piRNAs coordinated?}

Given its role as a putative male piRNA transcription factor, we expected that deletion of snpc-1.3 would result in loss of male piRNAs with no consequences to the expression of female piRNAs. However, loss of snpc-1.3 also results in increased female piRNA expression during spermatogenesis (Figure 3), whereas ectopic overexpression of snpc-1.3 during oogenesis leads to decreased female piRNA levels (Figure 5). Taken together, our findings suggest that transcription of male and female piRNAs is not completely separable from each other and that the balance in expression of the two piRNA subclasses may be dictated by the allocation of shared core transcription factors such as SNPC-4.

Similar to multiple gene classes activated by general transcription factors (Levine et al., 2014), we speculate that male and female promoters compete for access to a limited pool of the core transcription complex, which includes SNPC-4, PRDE-1, TOFU-4, and TOFU-5 (Figure 1). Therefore, we propose a model in which the expression and binding of SNPC-1.3 to core piRNA factors serves to 'sequester' the core complex away from female promoters. Mechanistically, we posit that the core piRNA transcription complex is specified to female promoters, and that only upon association with SNPC-1.3 is the core machinery directed to male promoters. We predict that when SNPC-1.3 is absent, more SNPC-4 and other previously identified cofactors are available to transcribe female piRNAs. Conversely, overexpression of SNPC-1.3 leads to the disproportionate recruitment of the core machinery to male promoters, leading to the indirect downregulation of female piRNAs. By controlling male piRNA expression, SNPC-1.3 is crucial for maintaining the balance between male and female piRNA levels across development. 


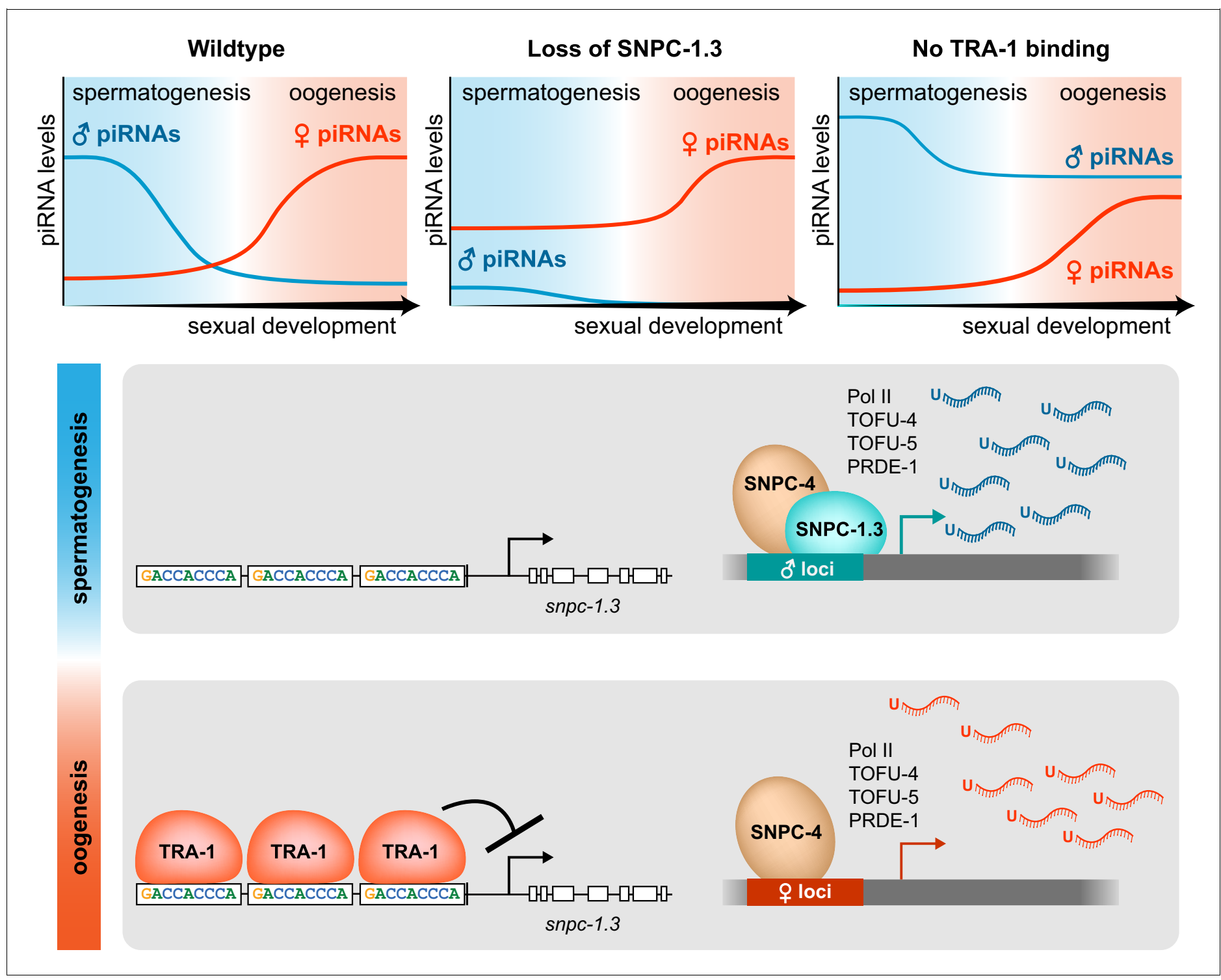

Figure 7. Model illustrating the dynamics of male and female piRNA transcription across $C$. elegans sexual development. In wild-type worms, male and female piRNA expression peaks during spermatogenesis and oogenesis, respectively. (Top) In snpc-1.3(-) mutants, male piRNA expression is abrogated, and female piRNA expression is moderately enhanced across sexual development relative to wild type. In TRA-1 binding site mutants, snpc1.3 expression is de-repressed causing ectopic upregulation of male piRNAs and moderate repression of female piRNA expression during oogenesis relative to wild type. (Bottom) During spermatogenesis, SNPC-1.3 interacts with SNPC-4 at male promoters to drive male piRNA transcription. During oogenesis, TRA-1 represses the transcription of snpc-1.3 which results in the suppression of male piRNA transcription, thus leading to enhanced transcription of female piRNAs.

While the default specification of the core complex to female promoters presents perhaps the most parsimonious explanation underlying male and female piRNA expression, we cannot exclude the possibility that an additional female-specific trans-acting factor may direct the core piRNA complex to female promoters. If true, we speculate that the developmental expression of such a factor (low during spermatogenesis and high during oogenesis), coupled with the developmental expression of SNPC-1.3, would coordinate the differential expression of male and female piRNAs. During spermatogenesis, SNPC-1.3 is more highly expressed such that the core machinery would primarily be directed to male promoters. In contrast, during oogenesis, SNPC-1.3 expression is low, concomitant with elevated expression of a female factor to license transcription of female piRNAs. This model, where both factors are present during both spermatogenesis and oogenesis, but in different 
ratios, would also be consistent with our piRNA expression analysis in snpc-1.3 loss-of-function and overexpression mutants.

\section{The piRNA pathway co-opts snRNA biogenesis machinery}

Our work adds to a growing body of evidence that snRNA machinery has been hijacked at multiple stages in C. elegans piRNA biogenesis, including transcription (Kasper et al., 2014; Weng et al., 2019) and termination (Beltran et al., 2019). Investigating potential parallels between snRNA and piRNA biogenesis may provide useful clues into the role of SNPC-1.3 in the piRNA complex.

The minimal snRNA SNAP complex consists of a 1:1:1 heterotrimer of the subunits SNAPC4, SNAPC1, and SNAPC3 in humans and SNAP190, SNAP43, and SNAP50 in flies (Henry et al., 1998; Hung and Stumph, 2011; Li et al., 2004; Ma and Hernandez, 2002; Mittal et al., 1999; Figure 1). In vitro studies have shown that the trimer must assemble before the complex is able to bind DNA. Similarly, our data show SNPC-1.3 requires SNPC-4 to bind at the piRNA clusters (Figure 4), although we cannot formally rule out that loss of SNPC-4 only affects the stability of SNPC-1.3, rather than directly recruiting SNPC-1.3 to piRNA promoters. We speculate the piRNA complex is assembled in a similar fashion to the snRNA complex. Based on this model, we expect that SNPC-4 binding at male piRNA loci is abolished in a snpc-1.3 mutant. However, conclusive evidence that SNPC-4 binding at male piRNA promoters requires SNPC-1.3 is still lacking. Due to the highly clustered nature of $C$. elegans piRNAs, we anticipate that detecting differences in SNPC-4 binding between male and female piRNAs in snpc-1.3(-) mutants may not be possible with traditional ChIPseq methods, and may require application of higher resolution techniques.

Given that piRNAs have co-opted trans-acting factors from snRNA biogenesis (Kasper et al., 2014), it would not be surprising if piRNAs also co-evolved cis-regulatory elements for transcription factor binding from snRNA loci. Recently, Beltran et al., 2019 identified similarity between the 3' end of PSEs of snRNA promoters and the eight nt piRNA core motif in nematodes. In addition, Pol II and Pol III transcription from snRNA promoters share a common PSE, but are distinguished by the presence of other unique motifs (Hung and Stumph, 2011). Correspondingly, the canonical Type I and less abundant Type II piRNAs can be discriminated by the presence or absence of the eight nt core motif, respectively. Factors such as TOFU-4 and TOFU-5 function in both Type I and II piRNA expression, whereas PRDE-1 is only required for Type I piRNAs (Kasper et al., 2014; Weng et al., 2019). Altogether, these observations highlight the importance of cis-regulatory elements in specifying the expression of snRNAs and piRNA classes. In addition to enrichment of cytosine at the $5^{\prime}$ position in the male core motif (Billi et al., 2013), we hypothesize that as-yet unidentified motifs may further discriminate male from female piRNA promoters. While we observed SNPC-1.3 binding to be enriched upstream of male piRNA loci (Figure 4), we cannot definitively conclude that SNPC-1.3 binds to the male-specific core motif, given the limitations of conventional ChIP-seq in resolving the SNPC-1.3 footprint. Identifying the factors that specifically bind the eight nt core motif and other potential cis-regulatory elements important for sex-specific piRNA expression will require further investigation.

\section{What are the functions of male piRNAs in C. elegans?}

Our data suggest that SNPC-1.3 is essential for proper spermiogenesis (Figure 6). We hypothesize the global loss of male piRNAs in a snpc-1.3(-) mutant is responsible for the higher incidence of spermiogenesis arrest and subsequent loss in fertility, although it is possible that SNPC-1.3 may have other or additional effects on male fertility. Characterization of prg-1(-) mutants during spermiogenesis agree with our findings that loss of piRNAs in the male germline leads to acute defects directly responsible for fertility (Wang and Reinke, 2008). Since the initial discovery of piRNA function in the targeting and silencing of transposons in Drosophila (Vagin et al., 2006; Brennecke et al., 2007), analyses in other systems have revealed that piRNAs have acquired neofunctions at later points along the evolutionary time scale (Ozata et al., 2019).

While it is estimated that as much as $45 \%$ of the human genome encodes for transposable elements (Lander et al., 2001), only 12\% of C. elegans genome encodes such elements. Furthermore, nearly all of these regions are inactive in C. elegans (Bessereau, 2006). In contrast to Drosophila piRNAs that target and silence transposons with perfect complementarity (Brennecke et al., 2007), C. elegans piRNAs are thought to bind a broad range of endogenously expressed transcripts by 
partial complementarity (Ashe et al., 2012; Shen et al., 2018; Zhang et al., 2018). Together, these findings suggest that worm piRNAs function in capacities distinct from canonical transposon silencing. While a recent methodology used crosslinking, ligation, and sequencing of piRNA:target hybrids $(\mathrm{CLASH})$ to determine that female piRNAs engage with almost every germline transcript (Shen et alo, 2018), how female piRNAs select their targets has yet to be examined. Like piRNAs characterized in the female germline, male piRNAs may be interfacing with a broad range of targets to regulate gene expression for proper spermatogenesis. Loss of prg-1 in males causes the downregulation of a subset of spermatogenesis-specific genes (Wang and Reinke, 2008), suggesting male piRNAs serve a protective function for spermatogenic processes. The characterization of the in vivo landscape of male piRNA target selection using CLASH may provide insights into piRNA function during spermatogenesis.

\section{Why are male piRNAs restricted from the female germline?}

Sperm and oocytes pass epigenetic information such as noncoding RNAs to the next generation (Hammoud et al., 2014; Brykczynska et al., 2010; Tabuchi et al., 2018; Kaneshiro et al., 2019). Recent studies show maternal piRNAs trigger the production of endo-siRNAs, called 22G-RNAs for their $5^{\prime}$ bias for guanine and 22 nt length, to transmit an epigenetic memory of foreign versus endogenous elements to the next generation (Ashe et al., 2012; Buckley et al.,, 2012; Shirayama et al., 2012). We predict that misexpression of male piRNAs during oogenesis may perturb the native pool of female piRNAs necessary for appropriate recognition of self versus non-self elements. This may explain the decrease in fertility we observed in multiple TRA-1 binding site mutant hermaphrodites (Figure 6-figure supplement 1B). As snpc-1.3 (3xtbs) sperm do not seem to exhibit significant morphological defects (Figure 6), the fertility defects in the snpc-1.3 (3xtbs) mutants could be due to problems arising in oogenesis. However, based on our sequencing data in snpc-1.3 (2xtbs) mutants, we cannot distinguish whether fertility defects during oogenesis are due to upregulation of male piRNAs, downregulation of female piRNAs, a combination of the two, or misexpression of downstream endo-siRNAs triggered by piRNAs. Further study of snpc-1.3 gain-offunction mutants in oogenesis will enhance our understanding of the physiological consequences of expressing male piRNAs in the female germline.

\section{The intersection between sex determination and sex specification of piRNA expression}

We speculate that gene duplication of the snpc- 1 family of genes occurred early during nematode evolution and allowed for the acquisition of new functions by snpc-1 paralogs, specifically, from snRNA to piRNA biogenesis. At least two SNPC-1 paralogs are present within the distantly related nematode species, Plectus sambesii. Furthermore, we predict that co-opting SNPC-1 paralogs for piRNA biogenesis may have occurred in parallel with the evolution of the nematode sex determination pathway. TRA-1 is a sex determination factor that acts to repress male-promoting gene expression in female germ cells to promote female germ cell fate. While Drosophila sex determination utilizes different factors than $C$. elegans, further investigation into the conservation of TRA-1 shows that it is a common feature in at least the nematode lineage (Pires-daSilva and Sommer, 2004). Additionally, just as we have shown that TRA-1 represses snpc-1.3 in C. elegans (Figure 5), TRA-1 binding motifs $\mathrm{GGG}(\mathrm{A} / \mathrm{T}) \mathrm{GG}$ are present in the putative upstream promoter regions of snpc-1.3 homologs identified in C. briggsae, C. brenneri, and C. nigoni (Figure 6-figure supplement 1C). Taken together, these analyses point to a conserved link between sex determination and piRNA biogenesis pathways among nematodes.

In summary, our work reveals that SNPC-1.3 is specified to the male germline and is essential for male piRNA expression. We have identified SNPC-1.3 as a major target of TRA-1 repression in the female germline. Future studies will likely uncover additional factors required to coordinate the proper balance of sex-specific piRNAs required for proper germline development and animal fertility. 


\section{Contact for reagent and resource sharing}

More details about resources and reagents can be found in the Key Resources Table found in Materials and methods. Further information and requests for resources and reagents should be directed to and will be fulfilled by the Lead Contact, John K. Kim (jnkim@jhu.edu).

\section{Experimental model and subject details}

C. elegans strains were maintained at $20^{\circ} \mathrm{C}$ according to standard procedures (Brenner, 1974), unless otherwise stated. Bristol N2 was used as the wild-type strain. Except for RNAi and ChIP experiments, worms were fed E. coli strain OP50. Worms used for ChIP were fed E. coli strain HB101.

\section{Materials and methods}

Key resources table

\begin{tabular}{|c|c|c|c|c|}
\hline $\begin{array}{l}\text { Reagent type } \\
\text { (species) or } \\
\text { resource }\end{array}$ & Designation & $\begin{array}{l}\text { Source or } \\
\text { reference }\end{array}$ & Identifiers & Additional information \\
\hline Antibody & $\begin{array}{l}\text { Mouse monoclonal } \\
\text { anti-Flag }\end{array}$ & Sigma & F1804; RRID: AB_262044 & Western - 1:1000; IF - 1:200 \\
\hline Antibody & $\begin{array}{l}\text { Rabbit polyclonal } \\
\text { anti-H3 }\end{array}$ & Abcam & Ab12079; RRID: AB_298834 & $1: 15,000$ \\
\hline Antibody & $\begin{array}{l}\text { Rabbit polyclonal } \\
\text { anti-tubulin }\end{array}$ & Sigma-Aldrich & T1450; RRID:AB_261655 & $1: 5000$ \\
\hline Antibody & $\begin{array}{l}\text { Goat polyclonal } \\
\text { anti-rabbit }\end{array}$ & $\begin{array}{l}\text { Jackson } \\
\text { Laboratories }\end{array}$ & 111035045; RRID:AB_2337938 & $1: 15,000$ \\
\hline Antibody & $\begin{array}{l}\text { Sheep polyclonal } \\
\text { anti-mouse }\end{array}$ & GE Healthcare & NA931; RRID:AB_772210 & $1: 5000$ \\
\hline Antibody & $\begin{array}{l}\text { Rat monoclonal } \\
\text { anti-Ollas }\end{array}$ & Novus Biologicals & NBP1-06713SS & Western - 1:8,000; IF - 1:200 \\
\hline Antibody & $\begin{array}{l}\text { Polyclonal donkey } \\
\text { anti-rabbit, } \\
\text { AlexaFluor } 488\end{array}$ & ThermoFisher & A-21208 & $1: 400$ \\
\hline Antibody & $\begin{array}{l}\text { Polyclonal goat anti- } \\
\text { mouse, AlexaFluor } \\
555\end{array}$ & ThermoFisher & A-21127 & $1: 400$ \\
\hline Antibody & $\begin{array}{l}\text { Polyclonal goat anti- } \\
\text { mouse IgG (IRDye } \\
800 \mathrm{CW} \text { ) }\end{array}$ & LI-COR Biosciences & 925-32210; RRID:AB_621842 & $1: 15,000$ \\
\hline Antibody & $\begin{array}{l}\text { Polyclonal goat anti- } \\
\text { rabbit IgG (IRDye } \\
680 \text { RD) }\end{array}$ & LI-COR Biosciences & 925-68071; RRID:AB_2721181 & $1: 15,000$ \\
\hline Other & DAPI & ThermoFisher & 62248 & $0.5 \mu \mathrm{g} / \mathrm{mL}$ \\
\hline Other & $\begin{array}{l}\text { Vectashield with } \\
\text { DAPI }\end{array}$ & Vector Laboratories & H-1200; RRID:AB_2336790 & \\
\hline Other & $\begin{array}{l}\text { Roche Blocking } \\
\text { Buffer }\end{array}$ & Millipore Sigma & 11096176001 & \\
\hline Other & $\begin{array}{l}\text { Odyssey Blocking } \\
\text { Buffer (TBS) }\end{array}$ & LI-COR Biosciences & $927-50003$ & \\
\hline $\begin{array}{l}\text { Strain, strain } \\
\text { background ( } E \text {. } \\
\text { coli) }\end{array}$ & OP50 & $\begin{array}{l}\text { Shared } \\
\text { Fermentation } \\
\text { Facility, } \\
\text { The Pennsylvania } \\
\text { State University }\end{array}$ & & \\
\hline
\end{tabular}

Continued on next page 
Continued

\begin{tabular}{|c|c|c|c|c|}
\hline $\begin{array}{l}\text { Reagent type } \\
\text { (species) or } \\
\text { resource }\end{array}$ & Designation & $\begin{array}{l}\text { Source or } \\
\text { reference }\end{array}$ & Identifiers & Additional information \\
\hline $\begin{array}{l}\text { Strain, strain } \\
\text { background ( } E \text {. } \\
\text { coli) }\end{array}$ & HB101 & $\begin{array}{l}\text { Shared } \\
\text { Fermentation } \\
\text { Facility, } \\
\text { The Pennsylvania } \\
\text { State University }\end{array}$ & & \\
\hline $\begin{array}{l}\text { Strain, strain } \\
\text { background ( } E \text {. } \\
\text { coli) }\end{array}$ & HT115 RNAi clones & $\begin{array}{l}\text { Kamath and } \\
\text { Ahringer, } 2003\end{array}$ & & \\
\hline Other & TriReagent & ThermoFisher & AM9738 & \\
\hline Other & Benzonase & Sigma-Aldrich & E1014 & $1: 1000$ \\
\hline Other & $\begin{array}{l}\text { RNA 5' } \\
\text { Polyphosphatase }\end{array}$ & Illumina & $\mathrm{RP} 8092 \mathrm{H}$ & \\
\hline Other & $\begin{array}{l}\text { Multiscribe Reverse } \\
\text { Transcriptase }\end{array}$ & ThermoFisher & 4311235 & \\
\hline Other & $\begin{array}{l}\text { Absolute Blue SYBR } \\
\text { Green }\end{array}$ & ThermoFisher & AB4166B & \\
\hline Other & $\begin{array}{l}\text { Dimethyl } \\
\text { pimelimidate } \\
\text { dihydrochloride }\end{array}$ & Sigma-Aldrich & D8388 & \\
\hline Other & $\begin{array}{l}\text { Protease inhibitor } \\
\text { cocktail }\end{array}$ & Roche & 4693159001 & $1: 100$ \\
\hline Other & Purelink RNAse A & ThermoFisher & 12091021 & $1: 10$ \\
\hline Other & Pronase $\mathrm{E}$ & Sigma-Aldrich & $7433-2$ & $20 \mu \mathrm{g} / \mathrm{mL}$ \\
\hline Other & $\begin{array}{l}\text { TaqMan Universal } \\
\text { PCR Master Mix, No } \\
\text { AmpErase UNG }\end{array}$ & ThermoFisher & 4324018 & \\
\hline $\begin{array}{l}\text { Sequence-based } \\
\text { reagent }\end{array}$ & U18 TaqMan probe & ThermoFisher & 1764 & $\begin{array}{l}\text { TGGCAGTGATGATCACAAATCCGTGTTTCTGA } \\
\text { CAAGCGATTGACGATAGAAAACCGGCTGAGCCA }\end{array}$ \\
\hline $\begin{array}{l}\text { Sequence-based } \\
\text { reagent }\end{array}$ & $\begin{array}{l}\text { 21UR-1848 TaqMan } \\
\text { probe }\end{array}$ & ThermoFisher & & UAAAGGCAGAAUUUUAUCAAC \\
\hline $\begin{array}{l}\text { Sequence-based } \\
\text { reagent }\end{array}$ & $\begin{array}{l}\text { 21UR-2502 TaqMan } \\
\text { probe }\end{array}$ & ThermoFisher & & UGAAAUUGUAGUAGACUGCUG \\
\hline $\begin{array}{l}\text { Sequence-based } \\
\text { reagent }\end{array}$ & $\begin{array}{l}\text { 21UR-4807 TaqMan } \\
\text { probe }\end{array}$ & ThermoFisher & & UGGGUGAAUUCUGUCCCGAAC \\
\hline $\begin{array}{l}\text { Sequence-based } \\
\text { reagent }\end{array}$ & $\begin{array}{l}\text { 21UR-1258 TaqMan } \\
\text { probe }\end{array}$ & ThermoFisher & & UAGACUUGAGUUAGAACGGUU \\
\hline $\begin{array}{l}\text { Sequence-based } \\
\text { reagent }\end{array}$ & $\begin{array}{l}\text { 21UR-3142 TaqMan } \\
\text { probe }\end{array}$ & ThermoFisher & & GUAGGGUCGUCUCUUGAGAGC \\
\hline $\begin{array}{l}\text { Sequence-based } \\
\text { reagent }\end{array}$ & $\begin{array}{l}\text { 21UR-3766 TaqMan } \\
\text { probe }\end{array}$ & ThermoFisher & & UGGAAGCUUGAUGGAAAAUGC \\
\hline $\begin{array}{l}\text { Commercial } \\
\text { assay kit }\end{array}$ & $\begin{array}{l}\text { NEBNext Multiplex } \\
\text { Small RNA Library } \\
\text { Prep Set for Illumina }\end{array}$ & $\begin{array}{l}\text { New England } \\
\text { Biolabs }\end{array}$ & E7330S & \\
\hline Other & Small RNA-seq data & This study & GEO: GSE152831 & \\
\hline Other & ChIP-seq data & This study & GEO: GSE152831 & \\
\hline Other & Mass spec data & This study & GEO: GSE152831 & \\
\hline $\begin{array}{l}\text { Strain, strain } \\
\text { background ( } C . \\
\text { elegans) }\end{array}$ & $\begin{array}{l}\text { wild-type, Bristol } \\
\text { isolate }\end{array}$ & CGC & N2 & \\
\hline $\begin{array}{l}\text { Strain, strain } \\
\text { background (C. } \\
\text { elegans) }\end{array}$ & prg-1(n4357) I & CGC & SX922 & \\
\hline
\end{tabular}

Continued on next page 
Continued

\begin{tabular}{|c|c|c|c|c|}
\hline $\begin{array}{l}\text { Reagent type } \\
\text { (species) or } \\
\text { resource }\end{array}$ & Designation & $\begin{array}{l}\text { Source or } \\
\text { reference }\end{array}$ & Identifiers & Additional information \\
\hline $\begin{array}{l}\text { Strain, strain } \\
\text { background ( } C . \\
\text { elegans) }\end{array}$ & $\begin{array}{l}\text { snpc-1.3(xk27)[snpc- } \\
1.3(\text { lof)] V }\end{array}$ & This study & QK171 & $\begin{array}{l}\text { For CRISPR/Cas9 reagents and methodology, } \\
\text { see Supplementary file } 4 \text { and Method details. }\end{array}$ \\
\hline $\begin{array}{l}\text { Strain, strain } \\
\text { background ( } C . \\
\text { elegans) }\end{array}$ & fem-1(hc17) IV & CGC & BA17 & \\
\hline $\begin{array}{l}\text { Strain, strain } \\
\text { background ( } C . \\
\text { elegans) }\end{array}$ & him-8(e1489) IV & CGC & CB1489 & \\
\hline $\begin{array}{l}\text { Strain, strain } \\
\text { background ( } C \text {. } \\
\text { elegans) }\end{array}$ & $\begin{array}{l}\text { snpc-1.3(xk28)[snpc- } \\
1.3(1 x t b s)] V\end{array}$ & This study & QK172 & $\begin{array}{l}\text { For CRISPR/Cas9 reagents and methodology, } \\
\text { see Supplementary file } 4 \text { and Method details. }\end{array}$ \\
\hline $\begin{array}{l}\text { Strain, strain } \\
\text { background ( } C \text {. } \\
\text { elegans) }\end{array}$ & $\begin{array}{l}\text { snpc-1.3(xk29)[snpc- } \\
1.3(2 x t b s)] V\end{array}$ & This study & OK173 & $\begin{array}{l}\text { For CRISPR/Cas9 reagents and methodology, } \\
\text { see Supplementary file } 4 \text { and Method details. }\end{array}$ \\
\hline $\begin{array}{l}\text { Strain, strain } \\
\text { background ( } C . \\
\text { elegans) }\end{array}$ & $\begin{array}{l}\text { snpc-1.3(xk30)[snpc- } \\
1.3(3 x t b s)] V\end{array}$ & This study & OK174 & $\begin{array}{l}\text { For CRISPR/Cas9 reagents and methodology, } \\
\text { see Supplementary file } 4 \text { and Method details. }\end{array}$ \\
\hline $\begin{array}{l}\text { Strain, strain } \\
\text { background ( } C . \\
\text { elegans) }\end{array}$ & $\begin{array}{l}\text { snpc- } 4(x k 31)[\text { snpc- } \\
4:: 3 x f l a g] I\end{array}$ & This study & OK175 & $\begin{array}{l}\text { For CRISPR/Cas9 reagents and methodology, } \\
\text { see Supplementary file } 4 \text { and Method details. }\end{array}$ \\
\hline $\begin{array}{l}\text { Strain, strain } \\
\text { background ( } C . \\
\text { elegans) }\end{array}$ & $\begin{array}{l}\text { snpc-4(xk31)[snpc- } \\
4:: 3 x f l a g] ~ I ; \text { fem-1 } \\
\text { (hc17) IV }\end{array}$ & This study & QK176 & $\begin{array}{l}\text { For CRISPR/Cas9 reagents and methodology, } \\
\text { see Supplementary file } 4 \text { and Method details. }\end{array}$ \\
\hline $\begin{array}{l}\text { Strain, strain } \\
\text { background ( } C \text {. } \\
\text { elegans) }\end{array}$ & $\begin{array}{l}\text { snpc-4(xk31)[snpc- } \\
4:: 3 x f l a g] \text { I; him-8 } \\
\text { (e1489) IV }\end{array}$ & This study & QK177 & $\begin{array}{l}\text { For CRISPR/Cas9 reagents and methodology, } \\
\text { see Supplementary file } 4 \text { and Method details. }\end{array}$ \\
\hline $\begin{array}{l}\text { Strain, strain } \\
\text { background ( } C . \\
\text { elegans) }\end{array}$ & $\begin{array}{l}\text { snpc-1.3(xk27)[snpc- } \\
1.3(\text { lof)] } V ; \text { fem-1 } \\
\text { (hc17) IV }\end{array}$ & This study & QK178 & $\begin{array}{l}\text { For CRISPR/Cas9 reagents and methodology, } \\
\text { see Supplementary file } 4 \text { and Method details. }\end{array}$ \\
\hline $\begin{array}{l}\text { Strain, strain } \\
\text { background ( } C . \\
\text { elegans) }\end{array}$ & $\begin{array}{l}\text { snpc-1.3(xk27)[snpc- } \\
1.3(\mathrm{lof})] \mathrm{V} ; \mathrm{him}-8 \\
(\mathrm{e} 1489) \text { IV }\end{array}$ & This study & QK179 & $\begin{array}{l}\text { For CRISPR/Cas9 reagents and methodology, } \\
\text { see Supplementary file } 4 \text { and Method details. }\end{array}$ \\
\hline $\begin{array}{l}\text { Strain, strain } \\
\text { background ( } C . \\
\text { elegans) }\end{array}$ & $\begin{array}{l}\text { mals105[col-19:: } \\
\text { GFP] V }\end{array}$ & Xantha Karp lab & XV33 & \\
\hline $\begin{array}{l}\text { Strain, strain } \\
\text { background ( } C . \\
\text { elegans) }\end{array}$ & $\begin{array}{l}\text { snpc-1.3(xk27)[snpc- } \\
1.3(\text { lof)] V; mals105 V }\end{array}$ & This study & QK180 & $\begin{array}{l}\text { For CRISPR/Cas9 reagents and methodology, } \\
\text { see Supplementary file } 4 \text { and Method details. }\end{array}$ \\
\hline $\begin{array}{l}\text { Strain, strain } \\
\text { background ( } C . \\
\text { elegans) }\end{array}$ & $\begin{array}{l}\text { snpc-4(xk31)[snpc- } \\
4:: 3 x f l a g] ~ I, \text { snpc- } 1.3 \\
(x k 27)[\text { snpc- } 1.3(\text { lof })] \\
V\end{array}$ & This study & QK181 & $\begin{array}{l}\text { For CRISPR/Cas9 reagents and methodology, } \\
\text { see Supplementary file } 4 \text { and Method details. }\end{array}$ \\
\hline $\begin{array}{l}\text { Strain, strain } \\
\text { background ( } C . \\
\text { elegans) }\end{array}$ & $\begin{array}{l}\text { snpc-4(xk23) I [snpc- } \\
4:: a i d:: \text { ollas] }\end{array}$ & This study & QK162 & $\begin{array}{l}\text { For CRISPR/Cas9 reagents and methodology, } \\
\text { see Supplementary file } 4 \text { and Method details. }\end{array}$ \\
\hline $\begin{array}{l}\text { Strain, strain } \\
\text { background ( } C . \\
\text { elegans) }\end{array}$ & $\begin{array}{l}\text { snpc-4(xk23) I; unc- } \\
11(e d 3) \text { III; ieSi38 IV }\end{array}$ & This study & QK163 & $\begin{array}{l}\text { For CRISPR/Cas9 reagents and methodology, } \\
\text { see Supplementary file } 4 \text { and Method details. }\end{array}$ \\
\hline $\begin{array}{l}\text { Strain, strain } \\
\text { background ( } C . \\
\text { elegans) }\end{array}$ & $\begin{array}{l}\text { unc-11(ed3) III; } \\
\text { ieSi38 IV [sun-1p:: } \\
\text { TIR1::mRuby::sun-1 } \\
\text { 3' } \\
\text { UTR + Crb-unc-119 } \\
\text { (+)] IV }\end{array}$ & CGC & CA1199 & \\
\hline
\end{tabular}

Continued on next page 
Continued

\begin{tabular}{|c|c|c|c|c|}
\hline $\begin{array}{l}\text { Reagent type } \\
\text { (species) or } \\
\text { resource }\end{array}$ & Designation & $\begin{array}{l}\text { Source or } \\
\text { reference }\end{array}$ & Identifiers & Additional information \\
\hline $\begin{array}{l}\text { Strain, strain } \\
\text { background ( } C . \\
\text { elegans) }\end{array}$ & $g / p-4(b n 2) I$ & CGC & SS104 & \\
\hline $\begin{array}{l}\text { Strain, strain } \\
\text { background ( } C \text {. } \\
\text { elegans) }\end{array}$ & $\begin{array}{l}\text { snpc-1.3(xk32)[snpc- } \\
1.3 a:: 3 x f l a g] V\end{array}$ & This study & OK182 & $\begin{array}{l}\text { For CRISPR/Cas9 reagents and methodology, } \\
\text { see Supplementary file } 4 \text { and Method details. }\end{array}$ \\
\hline $\begin{array}{l}\text { Strain, strain } \\
\text { background ( } C \text {. } \\
\text { elegans) }\end{array}$ & $\begin{array}{l}\text { glp-4(bn2) l; snpc- } \\
\text { 1.3(xk32)[snpc- } \\
\text { 1.3a::3xflag] V }\end{array}$ & This study & OK183 & $\begin{array}{l}\text { For CRISPR/Cas9 reagents and methodology, } \\
\text { see Supplementary file } 4 \text { and Method details. }\end{array}$ \\
\hline $\begin{array}{l}\text { Strain, strain } \\
\text { background ( } C \text {. } \\
\text { elegans) }\end{array}$ & $\begin{array}{l}\text { snpc-1.3(xk33)[snpc- } \\
\text { 1.3a::ollas] V }\end{array}$ & This study & QK184 & $\begin{array}{l}\text { For CRISPR/Cas9 reagents and methodology, } \\
\text { see Supplementary file } 4 \text { and Method details. }\end{array}$ \\
\hline $\begin{array}{l}\text { Strain, strain } \\
\text { background ( } C \text {. } \\
\text { elegans) }\end{array}$ & $\begin{array}{l}\text { snpc-4(xk31)[snpc- } \\
4:: 3 x f l a g] ~ I, \text { snpc-1.3 } \\
\text { (xk33)[snpc-1.3a:: } \\
\text { ollas] V }\end{array}$ & This study & QK185 & $\begin{array}{l}\text { For CRISPR/Cas9 reagents and methodology, } \\
\text { see Supplementary file } 4 \text { and Method details. }\end{array}$ \\
\hline $\begin{array}{l}\text { Strain, strain } \\
\text { background ( } C . \\
\text { elegans) }\end{array}$ & $\begin{array}{l}\text { prde-1(xk34)[prde- } \\
1:: \text { ollas] V }\end{array}$ & This study & QK186 & $\begin{array}{l}\text { For CRISPR/Cas9 reagents and methodology, } \\
\text { see Supplementary file } 4 \text { and Method details. }\end{array}$ \\
\hline $\begin{array}{l}\text { Strain, strain } \\
\text { background ( } C \text {. } \\
\text { elegans) }\end{array}$ & $\begin{array}{l}\text { snpc-4(xk31)[snpc- } \\
4:: 3 x f l a g] ~ l ; p r d e-1 \\
\text { (xk34)[prde-1::ollas] } \\
V\end{array}$ & This study & OK187 & $\begin{array}{l}\text { For CRISPR/Cas9 reagents and methodology, } \\
\text { see Supplementary file } 4 \text { and Method details. }\end{array}$ \\
\hline $\begin{array}{l}\text { Strain, strain } \\
\text { background ( } C . \\
\text { elegans) }\end{array}$ & $\begin{array}{l}\text { snpc-4(xk35)[snpc- } \\
4:: \text { ollas] I }\end{array}$ & This study & QK188 & $\begin{array}{l}\text { For CRISPR/Cas9 reagents and methodology, } \\
\text { see Supplementary file } 4 \text { and Method details. }\end{array}$ \\
\hline $\begin{array}{l}\text { Strain, strain } \\
\text { background ( } C . \\
\text { elegans) }\end{array}$ & $\begin{array}{l}\text { snpc-4(xk35)[snpc- } \\
4:: 0 \text { llas] l; snpc-1.3 } \\
\text { (xk32)[snpc- } \\
\text { 1.3a::3xflag] } \mathrm{V}\end{array}$ & This study & QK189 & $\begin{array}{l}\text { For CRISPR/Cas9 reagents and methodology, } \\
\text { see Supplementary file } 4 \text { and Method details. }\end{array}$ \\
\hline $\begin{array}{l}\text { Strain, strain } \\
\text { background ( } C \text {. } \\
\text { elegans) }\end{array}$ & $\begin{array}{l}\text { snpc-4(xk31)[snpc- } \\
4:: 3 x f l a g] ~ I ; \text { snpc-1.3 } \\
\text { (xk29)[snpc- } 1.3 \\
(2 x t b s)] V\end{array}$ & This study & QK190 & $\begin{array}{l}\text { For CRISPR/Cas9 reagents and methodology, } \\
\text { see Supplementary file } 4 \text { and Method details. }\end{array}$ \\
\hline $\begin{array}{l}\text { Strain, strain } \\
\text { background ( } C \text {. } \\
\text { elegans) }\end{array}$ & $\begin{array}{l}\text { snpc-4(xk23) I; unc- } \\
\text { 11(ed3) III; ieSi38 IV; } \\
\text { snpc-1.3(xk32)[snpc- } \\
\text { 1.3a::3xflag] V }\end{array}$ & This study & OK191 & $\begin{array}{l}\text { For CRISPR/Cas9 reagents and methodology, } \\
\text { see Supplementary file } 4 \text { and Method details. }\end{array}$ \\
\hline $\begin{array}{l}\text { Strain, strain } \\
\text { background ( } C . \\
\text { elegans) }\end{array}$ & $\begin{array}{l}\text { snpc-1.3(xk36)[snpc- } \\
1.3 a:: 3 x f l a g(2 x t b s)] V\end{array}$ & This study & QK192 & $\begin{array}{l}\text { For CRISPR/Cas } 9 \text { reagents and methodology, } \\
\text { see Supplementary file } 4 \text { and Method details. }\end{array}$ \\
\hline $\begin{array}{l}\text { Strain, strain } \\
\text { background ( } C . \\
\text { elegans) }\end{array}$ & $\begin{array}{l}\text { tra-1(xk37)[3xflag:: } \\
\text { tra-1] III }\end{array}$ & This study & QK193 & $\begin{array}{l}\text { For CRISPR/Cas } 9 \text { reagents and methodology, } \\
\text { see Supplementary file } 4 \text { and Method details. }\end{array}$ \\
\hline $\begin{array}{l}\text { Strain, strain } \\
\text { background ( } C \text {. } \\
\text { elegans) }\end{array}$ & $\begin{array}{l}\text { tra-1(xk37)[3xflag:: } \\
\text { tra-1] III; snpc- } 1.3 \\
(x k 28)[\text { snpc- } 1.3 \\
(1 x t b s)] V\end{array}$ & This study & QK194 & $\begin{array}{l}\text { For CRISPR/Cas9 reagents and methodology, } \\
\text { see Supplementary file } 4 \text { and Method details. }\end{array}$ \\
\hline $\begin{array}{l}\text { Strain, strain } \\
\text { background ( } C \text {. } \\
\text { elegans) }\end{array}$ & $\begin{array}{l}\text { tra-1(xk37)[3xflag:: } \\
\text { tra-1] III; snpc-1.3 } \\
(x k 29)[s n p c-1.3 \\
(2 x t b s)] V\end{array}$ & This study & QK195 & $\begin{array}{l}\text { For CRISPR/Cas9 reagents and methodology, } \\
\text { see Supplementary file } 4 \text { and Method details. }\end{array}$ \\
\hline $\begin{array}{l}\text { Strain, strain } \\
\text { background ( } C . \\
\text { elegans) }\end{array}$ & $\begin{array}{l}\text { tra-1(xk37)[3xflag:: } \\
\text { tra-1] III; snpc-1.3 } \\
(x k 30)[\text { snpc-1.3 } \\
(3 x+b s)] \mathrm{V}\end{array}$ & This study & OK196 & $\begin{array}{l}\text { For CRISPR/Cas9 reagents and methodology, } \\
\text { see Supplementary file } 4 \text { and Method details. }\end{array}$ \\
\hline
\end{tabular}

Continued on next page 
Continued

\begin{tabular}{|c|c|c|c|c|}
\hline $\begin{array}{l}\text { Reagent type } \\
\text { (species) or } \\
\text { resource }\end{array}$ & Designation & $\begin{array}{l}\text { Source or } \\
\text { reference }\end{array}$ & Identifiers & Additional information \\
\hline $\begin{array}{l}\text { Strain, strain } \\
\text { background ( } C . \\
\text { elegans) }\end{array}$ & $\begin{array}{l}\text { snpc-1.3(xk38) } \\
{[\text { snpc-1.3b::3xflag] } V}\end{array}$ & This study & QK197 & $\begin{array}{l}\text { For CRISPR/Cas9 reagents and methodology, } \\
\text { see Supplementary file } 4 \text { and Method details. }\end{array}$ \\
\hline $\begin{array}{l}\text { Software, } \\
\text { algorithm }\end{array}$ & bbmap 38.23 & $\begin{array}{l}\text { http://jgi.doe.gov/ } \\
\text { data-and-tools/bb- } \\
\text { tools }\end{array}$ & & \\
\hline $\begin{array}{l}\text { Software, } \\
\text { algorithm }\end{array}$ & Bowtie 1.1.1 & $\begin{array}{l}\text { Langmead et al., } \\
2009\end{array}$ & & \\
\hline $\begin{array}{l}\text { Software, } \\
\text { algorithm }\end{array}$ & Bowtie2 2.3.4.2 & $\begin{array}{l}\text { Langmead and } \\
\text { Salzberg, } 2012\end{array}$ & & \\
\hline $\begin{array}{l}\text { Software, } \\
\text { algorithm }\end{array}$ & CASHX 2.3 & $\begin{array}{l}\text { Fahlgren et al., } \\
2009\end{array}$ & & \\
\hline $\begin{array}{l}\text { Software, } \\
\text { algorithm }\end{array}$ & deepTools 3.3.1 & $\begin{array}{l}\text { Ramírez et al., } \\
2016\end{array}$ & & \\
\hline $\begin{array}{l}\text { Software, } \\
\text { algorithm }\end{array}$ & DESeq2 1.18.1 & Love et al., 2014 & & \\
\hline $\begin{array}{l}\text { Software, } \\
\text { algorithm }\end{array}$ & DESeq2 1.26 .0 & Love et al., 2014 & & \\
\hline $\begin{array}{l}\text { Software, } \\
\text { algorithm }\end{array}$ & FastQC 0.11 .7 & $\begin{array}{l}\text { http://www. } \\
\text { bioinformatics. } \\
\text { babraham.ac.uk/ } \\
\text { projects/fastqc/ }\end{array}$ & & \\
\hline $\begin{array}{l}\text { Software, } \\
\text { algorithm }\end{array}$ & GraphPad Prism & $\begin{array}{l}\text { https://www. } \\
\text { graphpad.com }\end{array}$ & & \\
\hline $\begin{array}{l}\text { Software, } \\
\text { algorithm }\end{array}$ & ImageJ & ImageJ & & \\
\hline $\begin{array}{l}\text { Software, } \\
\text { algorithm }\end{array}$ & MACS 2.1.2 & Zhang et al., 2008 & & \\
\hline $\begin{array}{l}\text { Software, } \\
\text { algorithm }\end{array}$ & MEME suite 5.1 .1 & Bailey et al., 2009 & & \\
\hline $\begin{array}{l}\text { Software, } \\
\text { algorithm }\end{array}$ & RStudio 3.4 .1 & $\begin{array}{l}\text { https://www.rstudio. } \\
\text { com }\end{array}$ & & \\
\hline $\begin{array}{l}\text { Software, } \\
\text { algorithm }\end{array}$ & Samtools 1.9 & Li et al., 2009 & & \\
\hline $\begin{array}{l}\text { Software, } \\
\text { algorithm }\end{array}$ & Subread 1.6.3 & Liao et al., 2014 & & \\
\hline $\begin{array}{l}\text { Software, } \\
\text { algorithm }\end{array}$ & Trim Galore! 0.5.0 & $\begin{array}{l}\text { http://www. } \\
\text { bioinformatics. } \\
\text { babraham.ac.uk/ } \\
\text { projects/trim_ } \\
\text { galore/ }\end{array}$ & & \\
\hline $\begin{array}{l}\text { Software, } \\
\text { algorithm }\end{array}$ & Trimmomatic 0.39 & Bolger et al., 2014 & & \\
\hline Other & $\begin{array}{l}\text { Dynabeads Protein } \\
\text { G }\end{array}$ & ThermoFisher & 10004D & \\
\hline Other & $\begin{array}{l}\text { Dynabeads M280 } \\
\text { sheep anti-mouse } \\
\text { lgG }\end{array}$ & ThermoFisher & $11202 D$ & \\
\hline Other & $\begin{array}{l}\text { SuperScript III } \\
\text { Reverse } \\
\text { Transcriptase }\end{array}$ & ThermoFisher & 18080085 & \\
\hline
\end{tabular}




\section{Generations of strains}

CRISPR/Cas9-generated strains were created as described in Paix et al., 2015 and are listed in Supplementary file 4. crRNA and repair template sequences of CRISPR-generated strains are listed in Supplementary file 4. After initial phenotyping of snpc-1.3a::3xflag and snpc-1.3b::3xflag (Figure 1-figure supplement 1C-G), snpc-1.3a::3xflag was used for all subsequent experiments (and is referred to as snpc-1.3::3xflag).

\section{RNAi assays}

Bacterial RNAi clones were grown from the Ahringer RNAi library (Kamath and Ahringer, 2003). Synchronized L1 worms were plated on HT115 bacteria expressing dsRNA targeting the gene interest or L4440 empty vector as a negative control as previously described (Timmons and Fire, 1998). All RNAi experiments were performed at $20^{\circ} \mathrm{C}$ unless otherwise stated.

\section{RNA extraction, library preparation, and sequencing}

After hypochlorite preparation and hatching in M9 buffer, snpc-4::aid::ollas and snpc-4::aid::ollas; Psun-1::TIR1 worms were transferred from NGM plates to plates containing $250 \mu \mathrm{M}$ auxin $20 \mathrm{hr}$ before collecting L4 and gravid worms, $48 \mathrm{hr}$ and $72 \mathrm{hr}$ after plating L1 worms at $20^{\circ} \mathrm{C}$, respectively. Worms were collected in TriReagent (ThermoFisher Scientific) and subjected to three freeze-thaw cycles. Following addition of 1-bromo-3-chloropropane, the aqueous phase was then precipitated with isopropanol at $-80^{\circ} \mathrm{C}$ for $2 \mathrm{hr}$. To pellet RNA, samples were spun at $21,000 \times \mathrm{g}$ for $30 \mathrm{~min}$ at $4^{\circ}$ C. After three washes in $75 \%$ ethanol, the pellet was resuspended in water.

RNA concentration and quality were measured using a TapeStation (Agilent Technologies). We size-selected small RNAs of 16-30 nt in length from $5 \mu \mathrm{g}$ total RNA on 17\% denaturing polyacrylamide gels. Small RNAs were treated with $5^{\prime}$ polyphosphatase (Illumina) to reduce $5^{\prime}$ triphosphate groups to monophosphates to enable $5^{\prime}$ adapter ligation. Small RNA-sequencing libraries were prepared using the NEBNext Multiplex Small RNA Library Prep Set for Illumina (NEB). Small RNA amplicons were size-selected on $10 \%$ polyacrylamide gels and quantified using qRT-PCR. Samples for each developmental time point were pooled into a single flow cell and single-end, $75 \mathrm{nt}$ reads were generated on a NextSeq 500 (Illumina). An average of 42.01 million reads (range 33.05-50.39 million) was obtained for each library.

\section{Quantitative RT-PCR}

Taqman cDNA synthesis was performed as previously described (Weiser et al., 2017). Briefly, for quantification of piRNA levels, TaqMan small RNA probes were designed and synthesized by Applied Biosystems. All piRNA species assessed by qPCR were normalized to U18 small nucleolar RNA. Fifty nanograms of total RNA was used for cDNA synthesis. cDNA was synthesized by Multiscribe Reverse Transcriptase (Applied Biosystems) using the Eppendorf Mastercycler Pro S6325 (Eppendorf). Detection of small RNAs was performed using the TaqMan Universal PCR Master Mix and No AmpErase UNG (Applied Biosystems). For quantification of mRNA levels, cDNA was made using 500 ng of total RNA using Multiscribe Reverse Transcriptase (Applied Biosystems). For quantification of snRNA levels, cDNA was made using $250 \mathrm{ng}$ of total RNA using SuperScript III Reverse Transcriptase (ThermoFisher). Assays for mRNA and snRNA levels were performed with Absolute Blue SYBR Green (ThermoFisher) and normalized to eft-2 using CFX63 Real Time System Thermocyclers (Bio-Rad). All qPCR primers used are listed in Supplementary file 4.

\section{Covalent crosslinking of Dynabeads}

Protein G Dynabeads (ThermoFisher Scientific, 1003D) were coupled to monoclonal mouse antiFLAG antibody M2 (Sigma-Aldrich, F1804). After three washes in $1 \times$ PBST (0.1\% Tween), Dynabeads were resuspended with $1 \times$ PBST with antibody, for a final concentration of $50 \mu \mathrm{g}$ antibody per 100 $\mu \mathrm{L}$ beads. The antibody-bead mixture was nutated for $1 \mathrm{hr}$ at room temperature. After three washes in $1 \times$ PBST and two washes in $0.2 \mathrm{M}$ sodium borate $\mathrm{pH} 9.0$, beads were nutated in $22 \mathrm{mM}$ DMP (Sigma-Aldrich, D8388) in $0.2 \mathrm{M}$ sodium borate for $30 \mathrm{~min}$ at room temperature. Following two washes in ethanolamine buffer $(0.2 \mathrm{M}$ ethanolamine, $0.2 \mathrm{M} \mathrm{NaCl} \mathrm{pH} \mathrm{8.5),} \mathrm{beads} \mathrm{were} \mathrm{nutated} \mathrm{for} 1$ $\mathrm{hr}$ at room temperature in the same buffer. Beads were placed into the same volume of ethanolamine buffer as the starting bead volume for storage at $4^{\circ} \mathrm{C}$ until use. 


\section{Immunoprecipitation for mass spectrometry, co-IP experiments, and expression}

For SNPC-4 IP mass spectrometry, synchronized populations of $2200,000,000$ him-8(e1489) L4s and $\sim 50,000,000$ fem-1(hc17) females were grown at $25^{\circ} \mathrm{C}$ and collected on OP50. For co-IP experiments, $\sim 500,000 \mathrm{L4}$ and $\sim 250,000,000$ gravid worms were grown and collected from OP50 plates. Due to low expression of SNPC-1.3 and appearance of background bands, samples examining SNPC-1.3 expression were subjected to immunoprecipitation before western blotting. For g/p-4 (bn2), him-8(e1489), and fem-1(hc17) temperature-shift experiments, worms were grown at $15^{\circ} \mathrm{C}$ before hypochlorite treatment to isolate embryos. Synchronized L1s were then transferred to $25^{\circ} \mathrm{C}$. For SNPC-1.3 expression in males and females, snpc-1.3::3xflag; him-8(e1489) L4 worms and snpc1.3::3xflag; fem-1(hc17) adult worms were collected.

Unless otherwise stated, all samples for mass spectrometry, co-IP, and western blotting used in this study were subjected to the following procedure. After three washes in M9 and one wash in water, worms were frozen and ground using the Retsch MM400 ball mill homogenizer for two rounds of $1 \mathrm{~min}$ at $30 \mathrm{~Hz}$. Frozen worm powder was resuspended in $1 \times$ lysis buffer used previously (Moissiard et al., 2014, $50 \mathrm{mM}$ Tris- $\mathrm{HCl}$ pH 8.0, $150 \mathrm{mM} \mathrm{NaCl}, 5 \mathrm{mM} \mathrm{MgCl}$, 1 mM EGTA, $0.1 \%$ NP- $40,10 \%$ glycerol) and protease inhibitor cocktail (Roche). After Bradford assay (ThermoFisher Scientific), lysates were normalized using lysis buffer and protease inhibitor. Benzonase (Sigma-Aldrich, E1014) was added to a final concentration of $1 \mu \mathrm{L} / \mathrm{mL}$ of lysate and nutated for 10 $\min$ at $4^{\circ} \mathrm{C}$. After centrifugation for $10 \mathrm{~min}$ at $4,000 \times \mathrm{g}, 1 \mathrm{~mL}$ of supernatant was added to $50 \mu \mathrm{L}$ of crosslinked Dynabeads and nutated for $15 \mathrm{~min}$ at $4^{\circ} \mathrm{C}$. Samples were then washed three times in $1 \times$ lysis buffer with protease inhibitors before $1 \mathrm{hr}$ nutation in $50 \mu \mathrm{L}$ of $2 \mathrm{mg} / \mathrm{mL}$ FLAG peptide (SigmaAldrich, F4799) diluted in $1 \times$ lysis buffer. Complete eluate, as well as $5 \%$ of crude lysate (after addition of benzonase), input, pellet, and post-IP samples, were added to $2 \times$ Novex Tris-glycine sodium dodecyl sulfate sample buffer (ThermoFisher Scientific, LC2676) to $1 \times$. Samples were then subjected to western blotting as described below.

\section{Western blotting}

Co-IP samples and SNPC-1.3::3xFlag westerns in snpc-1.3 tbs mutants were run on either $8-16 \%$ or 8\% Novex WedgeWell Tris-glycine precast gels (ThermoFisher) and transferred to PVDF membrane (Millipore). Mouse anti-Flag, rat anti-Ollas, rabbit anti-gamma tubulin, and rabbit anti-H3 were used at 1:1000, 1:8000, 1:5000, and 1:15000, respectively. Anti-mouse and anti-rabbit (for tubulin) antibodies were used at 1:5,000. To blot for $\mathrm{H} 3$, anti-rabbit secondary was used at 1:15,000. Anti-rat antibodies were used at 1:8,000. Antibodies used were Sigma-Aldrich F1804 (mouse anti-Flag), Novus Biologicals NBP1-06713SS (rat anti-Ollas), Sigma-Aldrich T1450 (rabbit anti-gamma tubulin), Abcam ab1791 (rabbit anti-H3), GE Healthcare NA931 (sheep anti-mouse), and Jackson Laboratories 111035045 (goat anti-rabbit). Both high-sensitivity Amersham ECL Prime (GE Healthcare, RPN2232) (for SNPC-1.3 blotting) and regular sensitivity Pierce ECL (ThermoFisher, 32209) were used for exposure in a Bio-Rad ChemiDoc Touch system.

For measuring SNPC-1.3 expression levels in various backgrounds, input (for normalization) and immunoprecipitation samples were run on 10\% Novex WedgeWell Tris-glycine precast gels (ThermoFisher). Following transfer, the membrane was dried for $20 \mathrm{~min}$ at room temperature. The blot was then recharged in 100\% methanol for 1 min, followed by a water rinse and a wash in TBS for 2 min. Blocking was performed in LI-COR Odyssey Blocking Buffer (TBS). Primary antibodies were 1:1,000 mouse anti-Flag (Sigma-Aldrich F1804) and 1:5,000 rabbit anti-gamma-Tubulin (SigmaAldrich T1450) in LI-COR Odyssey Blocking Buffer with $0.1 \%$ Tween. Washes were performed in TBST (TBS + 0.1\% Tween). LI-COR IRDye 800CW goat anti-mouse IgG and 680RD goat anti-rabbit IgG were used at 1:15,000 in Odyssey Blocking Buffer with 0.1\% Tween and 0.01\% SDS. After three washes in TBST, the membranes were incubated in TBS before imaging in the LI-COR Odyssey Fc.

\section{Mass spectrometry and analysis}

Proteins were precipitated with 23\% TCA and washed with acetone. Protein pellets solubilized in 8 $\mathrm{M}$ urea, $100 \mathrm{mM}$ Tris $\mathrm{pH} \mathrm{8.5}$, and reduced with $5 \mathrm{mM}$ Tris (2-carboxyethyl)phosphine hydrochloride (Sigma-Aldrich, St. Louis, MO, product C4706) and alkylated with $55 \mathrm{mM}$ 2-chloroacetamide (Fluka Analytical, product 22790). Proteins were digested for $18 \mathrm{hr}$ at $37^{\circ} \mathrm{C}$ in $2 \mathrm{M}$ urea $100 \mathrm{mM}$ Tris pH 8.5, 
$1 \mathrm{mM} \mathrm{CaCl} 2$ with $2 \mu \mathrm{g}$ trypsin (Promega, Madison, WI, product V5111). Single-phase analysis (in replicate) was performed using a Dionex 3000 pump and a Thermo LTO Orbitrap Velos using an inhouse built electrospray stage (Wolters et al., 2001). Protein and peptide identification and protein quantitation were done with Integrated Proteomics Pipeline, IP2 (Integrated Proteomics Applications, Inc, San Diego, CA; http://www.integratedproteomics.com/). Tandem mass spectra were extracted from raw files using RawConverter (He et al., 2015) with monoisotopic peak option and were searched against protein database release WS260 from WormBase, with FLAG-tagged SNPC4, common contaminants and reversed sequences added, using ProLuCID (Peng et al., 2003; Xu et al., 2006). The search space included all fully tryptic and half-tryptic peptide candidates with a fixed modification of 57.02146 on C. Peptide candidates were filtered using DTASelect (Tabb et alo, 2002).

Using custom R scripts, average enrichment between SNPC-4::3xFlag and no-tag control immunoprecipitation experiments were calculated. For each experiment, enrichment was normalized by dividing the peptide count for each protein by the total peptide count. Adjusted p-values were calculated by applying the Bonferroni method using DESeq2 (Love et al., 2014). Although SNPC-3.1 and SNPC-3.2 are reported to have the same amino acid sequence, we have picked up differential peptide coverage in the fem-1(-) mutant for these two proteins and represented them as two different data points.

\section{Immunofluorescence microscopy}

Adult gonads were dissected into egg buffer ( $25 \mathrm{mM}$ HEPES pH 7.4, $118 \mathrm{mM} \mathrm{NaCl}, 48 \mathrm{mM} \mathrm{KCl}, 2$ $\mathrm{mM}$ EDTA, $0.5 \mathrm{mM}$ EGTA) with $30 \mathrm{mM}$ sodium azide and $0.1 \%$ Tween-20, and fixed for $10 \mathrm{~s}$ in $1 \%$ formaldehyde in egg buffer followed by $1 \mathrm{~min}$ in $100 \%$ methanol at $-20^{\circ} \mathrm{C}$. All washing and staining was completed in suspension. Germlines were blocked in normal goat serum or $1 \times$ Roche blocking buffer in PBST (PBS + 0.2\% Tween) for $30 \mathrm{~min}$ at room temperature. Primary mouse anti-Flag (Sigma F1804) and rat anti-Ollas (NBP1-06713SS) antibodies were used at 1:200 in blocking agent in PBST. AlexaFluor 555 goat anti-mouse and AlexaFluor 488 goat anti-rat secondary antibodies (ThermoFisher) were used at 1:400 in blocking agent in PBST. Germlines were stained with $0.5 \mu \mathrm{g} / \mathrm{mL}$ DAPI and then mounted in Vectashield with DAPI (Vector Laboratories H-1200). Images were acquired at $63 x$ on a Zeiss LSM700 confocal microscope. Publication images were acquired at $100 \times$ on a GE DeltaVision microscope. Image processing was performed using SoftWoRx to collect 3D image stacks, deconvolve (enhanced ratio, 20 cycles), and compile into a maximum intensity projection. Composite images were stitched and colored in Fiji using the Stitching plugin (Preibisch et alo, 2009).

\section{Chromatin immunoprecipitation, library prep, and sequencing}

Worms were grown in liquid culture as previously described (Zanin et al., 2011). $250 \mu \mathrm{M}$ auxin was added to snpc-1.3::3xflag; snpc-4::aid::ollas; Psun-1::TIR1 worms $4 \mathrm{hr}$ before collection at $48 \mathrm{hr}$ post$\mathrm{L} 1$ at $20^{\circ} \mathrm{C}$. After washing, the gut was cleared for 15 min by nutation in M9, followed by three washes in M9. Worms were live-crosslinked in $2.6 \%$ formaldehyde in water for $30 \mathrm{~min}$ at room temperature with nutation. Crosslinking was quenched with a final concentration of $125 \mathrm{mM}$ glycine for 5 min with nutation. After three washes with water, worms were flash-frozen in liquid nitrogen. Frozen worm pellets were ground into powder using the Retsch MM40 ball mill homogenizer for 2 rounds of $1 \mathrm{~min}$ at $30 \mathrm{~Hz}$. Frozen worm powder was resuspended in 1× RIPA buffer (1× PBS, 1\% $\mathrm{NP}-40,0.5 \%$ sodium deoxycholate, $0.1 \% \mathrm{SDS}$ ) for $10 \mathrm{~min}$ at $4^{\circ} \mathrm{C}$. Crosslinked chromatin was sonicated using a Diagenode Bioruptor Pico for three $3 \mathrm{~min}$ cycles, $30 \mathrm{~s}$ on/off. We nutated $10 \mu \mathrm{g}$ of chromatin overnight at $4^{\circ} \mathrm{C}$ with $2 \mu \mathrm{g}$ of Flag antibody (Sigma-Aldrich, F1804) and then for $1.5 \mathrm{hr}$ with $50 \mu \mathrm{L}$ mouse IgG Dynabeads (Invitrogen). Input amount was $10 \%$ of IP. Chromatin was de-crosslinked and extracted as described previously (Weiser et al., 2017). Individual input and IP samples of each genotype were processed for both sequencing and quantitative PCR.

Libraries were prepared and multiplexed using the Ovation Ultralow Library Systems v2 (NuGEN Technologies) according to the manufacturer's protocol. The Illumina HiSeq 4000 platform was used to generate $50 \mathrm{bp}$ single-end reads for SNPC-1.3 ChIP-seq libraries. The NovaSeq 6000 platform was used to generate $50 \mathrm{bp}$ paired-end reads for TRA-1 ChIP-seq libraries. 


\section{Quantitative PCR of ChIP samples}

ChIP DNA was eluted in $18 \mu \mathrm{L}$ of $1 \times \mathrm{TE} \mathrm{pH} 8.0$ and $2 \mu \mathrm{L}$ of $20 \mathrm{mg} / \mathrm{mL}$ RNase A (Invitrogen, ThermoFisher Scientific). For a final reaction volume of $25 \mu \mathrm{L}$, each reaction consisted of final $1 \times$ Absolute Blue SYBR Green (ThermoFisher Scientific), $35 \mathrm{nM}$ each of forward and reverse primer, and $2 \mu \mathrm{L}$ ChIP eluate. Reactions were performed in technical duplicates in a Bio-Rad CF96 Real Time PCR thermal cycler.

\section{Hermaphrodite fertility assays}

Gravid worms (previously maintained at $20^{\circ} \mathrm{C}$ ) were subjected to hypochlorite treatment, and their progeny were plated onto $\mathrm{NGM}$ at $25^{\circ} \mathrm{C}(\mathrm{PO})$. At the $\mathrm{L} 2$ or $\mathrm{L} 3$ stage, worms were singled onto individual plates and their progeny (F1) counted.

\section{Mating assays}

To test male-dependent rescue of fem-1(hc17) fertility, 10-12 hermaphrodites of each strain were grown at $20^{\circ} \mathrm{C}$ and embryos were isolated by allowing egg lay for $2 \mathrm{hr}$ before removal. Embryos were shifted to $25^{\circ} \mathrm{C}$, and upon reaching the L4 stage (24 hr), ten him-8(e1489) L4 males were transferred and mated with two fem-1(hc17) females. Brood size was quantified by counting when a majority of progeny had at least reached the young adult stage (about 3 days after transfer). To test the fertility of the hermaphrodites upon mating, 10-12 hermaphrodites of each strain were grown at $20^{\circ} \mathrm{C}$ and embryos were isolated after egg lay for $2 \mathrm{hr}$ before removal. Embryos were shifted to $25^{\circ} \mathrm{C}$ and 1ten col-19(GFP+) L4-staged males (24 hr) were then transferred with a single hermaphrodite (36 hr), and the number of live cross progeny was counted after reaching adulthood. Brood size was quantified by counting when the majority of progeny had at least reached the young adult stage (about 3 days after transfer).

\section{Sperm activation assay and imaging}

To perform sperm activation assays, spermatids were dissected from adult males that were shifted to $25^{\circ} \mathrm{C}$ during the embryo stage, and isolated prior to sexual maturity (about $48 \mathrm{hr}$ post-L1). Dissection was performed directly on glass slides in sperm medium $(50 \mathrm{mM} \mathrm{HEPES} \mathrm{pH} \mathrm{7.8,50} \mathrm{mM} \mathrm{NaCl,}$ $25 \mathrm{mM} \mathrm{KCl}, 5 \mathrm{mM} \mathrm{CaCl}_{2}$, and $1 \mathrm{mM} \mathrm{MgSO}_{4}$ ) supplemented with $20 \mu \mathrm{g} / \mathrm{mL}$ pronase $\mathrm{E}$ (Millipore Sigma). For the characterization of sperm morphology, sperm were imaged 30 min after the addition of pronase E. Individual sperm were manually categorized into two types: spermatids with normal pseudopods or spermatids with irregular or no pseudopods (Shakes and Ward, 1989). For Figure $6 E, Z$, stacks were imaged in $10 \mathrm{~s}$ intervals for $30 \mathrm{~min}$ and a representative in-focus stack was chosen at every $3 \mathrm{~min}$ interval. To characterize sperm activation dynamics, sperm were individually followed across $10 \mathrm{~s}$ intervals for $30 \mathrm{~min}$, and the different stages of sperm activation were designated into four categories based on these morphological changes: (1) undifferentiated spermatid, (2) spiky intermediate characterized by the presence of spike growth, (3) growing or motile pseudopod by the presence of a pseudopod, and (4) immobile sperm when little movement was observed either in the sperm body or pseudopod for longer than $30 \mathrm{~s}$. Statistical significance was assessed using Student's t-test.

\section{Quantitative and statistical analysis}

Unless otherwise stated, all quantitative analyses are shown as mean with standard deviation represented as error bars. For qRT-PCR, fertility and mating assays, and western blot, at least two independent experiments were performed; one representative biological replicate is shown.

\section{Small RNA-seq analysis}

Raw small RNA-seq reads were trimmed for Illumina adapters and quality (SLIDING WINDOW: 4:25) using Trimmomatic 0.39 (Bolger et al., 2014). Trimmed reads were then filtered using bbmap 38.23 (http://jgi.doe.gov/data-and-tools/bb-tools) to retain reads that were 15-30 nt in length. These filtered reads were aligned to the $C$. elegans WBcel235 (Cunningham et al., 2019) reference genome using Bowtie 1.1.1 (Langmead et al., 2009) with parameters -v 0 k 5 -best -strata -tryhard. Quality control of raw and aligned reads was performed using FastQC 0.11 .7 (http://www.bioinformatics. babraham.ac.uk/projects/fastqc/), SAMtools 1.9 (Li et al., 2009), and in-house Python and R scripts. 
Mapped reads were assigned to genomic features using featureCounts from Subread 1.6.3 (Liao et al., 2014), taking into account overlapping and multi-mapping reads (-O -M). Raw counts were normalized within DESeq2 1.26.0 (Love et al., 2014), and principal component analysis (PCA) was performed using the regularized log transform of normalized counts within DESeq2 (Figure 5figure supplement $1 C$ ). In addition, we distributed mapped reads by size and $5^{\prime}$ nucleotide identity to verify the presence of small RNA species such as 22G-RNAs and 21U-RNAs (Figure 3-figure supplement 2B, Figure 5 -figure supplement $1 B$ ).

To identify differentially expressed genes, DESeq2 was applied to piRNAs on chromosome IV. In this study (method 1), we define significant and differentially expressed genes as having an absolute value of $\log _{2}$ (fold-change) $\geq 0.26$ and FDR of $\leq 0.05$ (Benjamini-Hochberg). The $\log _{2}$ (fold-change) threshold and significance level were selected based on benchmarking the differential expression results against the Taqman piRNA expression assays. At the chosen cutoffs, differential expression analysis captures the Taqman assays results for the three male piRNAs (21UR-1258, 21UR-3142, and 21UR-3766) and three female piRNAs (21UR-1848, 21UR-2502, and 21UR-4817). Contrasts between mutant and wild type were designed without independent filtering.

For motif discovery, nucleotide sequences were extracted from the reference genome with $60 \mathrm{nt}$ upstream of each piRNA and submitted to the MEME suite 5.1.1 (Bailey et al., 2009). Results from MEME were used to generate the sequence logo plot with the median position of the C-nucleotide of the identified motif, number of piRNAs, and the associated E-value.

A second, independent small RNA-seq analysis workflow (described in Figure 3-figure supplement 1) was implemented to validate our results. Results produced from this analysis are provided in Figure 3-figure supplement 2. We parsed - small RNA sequences that were 16-30 nt from adapters. Reads with $>3 \mathrm{nt}$ falling below a quality score of $\mathrm{Q} 30$ were discarded. Reads were mapped to the C. elegans WS230 (Stein et al., 2001) reference genome using CASHX v. 2.3 (Fahlgren et al., 2009) allowing for 0 mismatches. Custom Perl, Awk, and R scripts were used to count features and to generate PCA and size distribution plots. Multi-mapping reads were assigned proportionally to each possible locus. Differential expression analysis was done using DESeq2 v. 1.18.1 (Love et al., 2014). A reporting threshold was set at an absolute value of $\log _{2}$ (fold-change) $\geq 0.26$ and a Benjamini-Hochberg-corrected $p \leq 0.20$.

\section{ChIP-seq analysis}

De-multiplexed raw ChIP-seq data in FASTO format were trimmed for adapters and sequencing quality score > Q25 using Trim Galore! 0.5.0 (http://www.bioinformatics.babraham.ac.uk/projects/ trim_galore/) and aligned to $C$. elegans reference genome WBcel235 (Cunningham et al., 2019) using Bowtie2 2.3.4.2 (Langmead and Salzberg, 2012) with default parameters. Post-alignment filtering was then performed to remove PCR duplicates using the MarkDuplicates utility within Picard 2.22.1 (http://broadinstitute.github.io/picard/). In addition, SAMtools 1.9 was applied to remove unmapped reads and reads that mapped with MAPQ 30 but were not of primary alignment or failed sequence platform quality checks (SAMtools -F 1804 -q 30) (Li et al., 2009).

To identify and visualize binding sites and peaks for SNPC-1.3 ChIP-seq, filtered SNPC-1.3 ChIPseq reads were extended to $200 \mathrm{bp}$ to account for the average length of ChIP fragments. We then partitioned the genome into consecutive, non-overlapping $1 \mathrm{~kb}$ bins and calculated read coverage, normalized by sequencing depth of each library, based on the total read count in each bin. Bins with read coverages in the IP sample that fell below the median read coverage of piRNA-depleted bins on chromosome IV in the relevant input control were excluded from further analysis. Bins containing only male, female, and non-enriched piRNAs (as defined by small RNA-seq analysis) were then extracted to generate binding profiles and heatmaps. For this, the bamCompare tool in deepTools 3.3.1 (Ramírez et al., 2016) was used to calculate the ratio between read coverage of each ChIP sample and input control (-scaleFactorsMethod None-normalizeUsing CPM -operation ratio-binSize 50 -ignoreForNormalization MtDNA -extendReads 200). The ENCODE ce11 blacklist (Amemiya et al., 2019) was also supplied (https://github.com/Boyle-Lab/Blacklist/). The bamCompare output was then used in deepTools computeMatrix to calculate scores for plotting profiles and heatmaps with deepTools plotProfile and plotHeatmap.

TRA-1 ChIP-seq peaks were called by callpeak within MACS 2.1.2 (Zhang et al., 2008) (-p-value 0.05 ) with filtered TRA-1 ChIP-seq reads and relevant input controls. TRA-1 signal tracks were generated by calculating fold enrichment from read count-normalized genome-wide pileup and lambda 
track outputs by callpeak (bdgcmp in MACS2). The ENCODE ce 11 blacklist (Amemiya et al., 2019) was supplied in this analysis (https://github.com/Boyle-Lab/Blacklist/). The bamCompare tool in deepTools 3.3.1 (Ramírez et al., 2016) was used to quantify read coverage of each ChIP sample and input control.

Reproducibility between SNPC-1.3 and TRA-1 ChIP-seq replicates (Figure 4-figure supplement 1C, Figure 5-figure supplement 1E) was assessed by applying deepTools bamCompare, as described above, and deepTools plotCorrelation to depict pairwise correlations between replicates and compute the Pearson correlation coefficient.

\section{Data and software availability}

The mass spectrometry, small RNA-seq, and ChIP-seq data have been deposited in NCBI under GEO accession number: GSE152831. Processed data and scripts used for analysis are available at https://github.com/starostikm/SNPC-1.3; Choi, 2021; copy archived at swh:1:rev: b23f652341d999150edf5ae9c8de72e9192b2843.

\section{Acknowledgements}

We thank Himani Galagali and Natasha Weiser for helpful comments on the manuscript. We thank members of the Kim Lab (Amelia Alessi, Mindy Clark, Gregory Fuller, Jessica Kirshner, Alex Rittenhouse, Darius Mostaghimi, Lars Benner), Tatjana Trcek, Jocelyn Haversat, Yumi Kim, Angela Andersen, Aurelia Mapps, and Jacqueline Tay for helpful suggestions. Computational resources were provided by the Maryland Advanced Research Computing Center (MARCC). Some strains were provided by the Caenorhabditis Genetics Center, which is funded by the NIH Office of Research Infrastructure Programs (P40 OD010440). This work was supported by grants from the NSF DGE1746891 (to RJT), NIH R35 GM130272 (to SEJ); NIH R35 GM119775 (to TAM); and NIH R01 GM129301 and NIH R01 GM118875 (to JKK).

\section{Additional information}

Funding

\begin{tabular}{|c|c|c|}
\hline Funder & Grant reference number & Author \\
\hline National Science Foundation & DGE-1746891 & Rebecca J Tay \\
\hline $\begin{array}{l}\text { National Institute of General } \\
\text { Medical Sciences }\end{array}$ & R35 GM130272 & $\begin{array}{l}\text { Suhua Feng } \\
\text { Steven E Jacobsen }\end{array}$ \\
\hline $\begin{array}{l}\text { National Institute of General } \\
\text { Medical Sciences }\end{array}$ & R35 GM119775 & $\begin{array}{l}\text { Brooke E Montgomery } \\
\text { Taiowa A Montgomery }\end{array}$ \\
\hline $\begin{array}{l}\text { National Institute of General } \\
\text { Medical Sciences }\end{array}$ & R01 GM12301 & $\begin{array}{l}\text { Charlotte P Choi } \\
\text { Rebecca J Tay } \\
\text { Margaret R Starostik } \\
\text { Emily Xu } \\
\text { Maya A Hammonds } \\
\text { John K Kim }\end{array}$ \\
\hline $\begin{array}{l}\text { National Institute of General } \\
\text { Medical Sciences }\end{array}$ & R01 GM118875 & $\begin{array}{l}\text { Charlotte P Choi } \\
\text { Rebecca J Tay } \\
\text { Margaret R Starostik } \\
\text { Emily Xu } \\
\text { Maya A Hammonds } \\
\text { John K Kim }\end{array}$ \\
\hline $\begin{array}{l}\text { National Institute of General } \\
\text { Medical Sciences }\end{array}$ & P41 GM103533 & $\begin{array}{l}\text { James J Moresco } \\
\text { John R Yates III III }\end{array}$ \\
\hline
\end{tabular}

The funders had no role in study design, data collection and interpretation, or the decision to submit the work for publication. 
Author contributions

Charlotte P Choi, Rebecca J Tay, Conceptualization, Data curation, Formal analysis, Investigation, Visualization, Methodology, Writing - original draft, Writing - review and editing; Margaret R Starostik, Data curation, Formal analysis, Visualization, Methodology, Writing - original draft; Suhua Feng, James J Moresco, Brooke E Montgomery, Emily Xu, Maya A Hammonds, John R Yates III, Steven E Jacobsen, Methodology; Michael C Schatz, Formal analysis, Supervision, Methodology; Taiowa A Montgomery, Formal analysis, Methodology; John K Kim, Conceptualization, Supervision, Funding acquisition, Methodology, Project administration, Writing - review and editing

\section{Author ORCIDs}

Charlotte P Choi (D) https://orcid.org/0000-0002-1857-6599

Rebecca J Tay (D) https://orcid.org/0000-0002-2270-0505

Margaret R Starostik (iD) https://orcid.org/0000-0002-5274-2765

Taiowa A Montgomery (iD) http://orcid.org/0000-0001-7857-3253

John R Yates III (iD) https://orcid.org/0000-0001-5267-1672

John K Kim (iD) https://orcid.org/0000-0001-9838-3254

Decision letter and Author response

Decision letter https://doi.org/10.7554/eLife.60681.sa1

Author response https://doi.org/10.7554/eLife.60681.sa2

\section{Additional files}

Supplementary files

- Supplementary file 1. Differential expression of piRNAs in wild-type worms during spermatogenesis and oogenesis. Related to Figure 3.

- Supplementary file 2. Differential expression of piRNAs in wild-type and snpc-1.3(-) mutants during spermatogenesis. Related to Figure 3.

- Supplementary file 3. Differential expression of piRNAs in wild type and snpc-1.3 (2xtbs) mutants during oogenesis. Related to Figure 5.

- Supplementary file 4. List of guide RNAs, repair templates, and oligos used in this study.

- Transparent reporting form

Data availability

Sequencing data have been deposited in GEO under accession code GSE152831. All data generated or analyzed during this study are included in the manuscript and supporting files. Source data files have been provided for Figures 1-6.

The following dataset was generated:

\begin{tabular}{|c|c|c|c|c|}
\hline Author(s) & Year & Dataset title & Dataset URL & Database and Identifier \\
\hline Starostik MR & 2020 & $\begin{array}{l}\text { SNPC-1.3 is a sex-specific } \\
\text { transcription factor that drives } \\
\text { male piRNAs in C. elegans }\end{array}$ & $\begin{array}{l}\text { https://www.ncbi.nlm. } \\
\text { nih.gov/geo/query/acc. } \\
\text { cgi?acc=GSE152831 }\end{array}$ & $\begin{array}{l}\text { NCBI Gene Expression } \\
\text { Omnibus, GSE152831 }\end{array}$ \\
\hline
\end{tabular}

\section{References}

Amemiya HM, Kundaje A, Boyle AP. 2019. The ENCODE blacklist: identification of problematic regions of the genome. Scientific Reports 9:9354. DOI: https://doi.org/10.1038/s41598-019-45839-z, PMID: 31249361

Andersen PR, Tirian L, Vunjak M, Brennecke J. 2017. A heterochromatin-dependent transcription machinery drives piRNA expression. Nature 549:54-59. DOI: https://doi.org/10.1038/nature23482, PMID: 28847004

Aravin AA, Lagos-Quintana M, Yalcin A, Zavolan M, Marks D, Snyder B, Gaasterland T, Meyer J, Tuschl T. 2003.

The small RNA profile during Drosophila melanogaster development. Developmental Cell 5:337-350.

DOI: https://doi.org/10.1016/S1534-5807(03)00228-4, PMID: 12919683 
Aravin A, Gaidatzis D, Pfeffer S, Lagos-Quintana M, Landgraf $\mathrm{P}$, lovino N, Morris $\mathrm{P}$, Brownstein MJ, KuramochiMiyagawa S, Nakano T, Chien M, Russo JJ, Ju J, Sheridan R, Sander C, Zavolan M, Tuschl T. 2006. A novel class of small RNAs bind to MILI protein in mouse testes. Nature 442:203-207. DOI: https://doi.org/10.1038/ nature04916, PMID: 16751777

Armisen J, Gilchrist MJ, Wilczynska A, Standart N, Miska EA. 2009. Abundant and dynamically expressed miRNAs, piRNAs, and other small RNAs in the vertebrate Xenopus tropicalis. Genome Research 19:1766-1775. DOI: https://doi.org/10.1101/gr.093054.109, PMID: 19628731

Ashe A, Sapetschnig A, Weick EM, Mitchell J, Bagijn MP, Cording AC, Doebley AL, Goldstein LD, Lehrbach NJ, Le Pen J, Pintacuda G, Sakaguchi A, Sarkies P, Ahmed S, Miska EA. 2012. piRNAs can trigger a multigenerational epigenetic memory in the germline of C. elegans. Cell 150:88-99. DOI: https://doi.org/10. 1016/j.cell.2012.06.018, PMID: 22738725

Bailey TL, Boden M, Buske FA, Frith M, Grant CE, Clementi L, Ren J, Li WW, Noble WS. 2009. MEME SUITE: tools for motif discovery and searching. Nucleic Acids Research 37:W202-W208. DOI: https://doi.org/10.1093/ nar/gkp335, PMID: 19458158

Batista PJ, Ruby JG, Claycomb JM, Chiang R, Fahlgren N, Kasschau KD, Chaves DA, Gu W, Vasale JJ, Duan S, Conte D, Luo S, Schroth GP, Carrington JC, Bartel DP, Mello CC. 2008. PRG-1 and 21U-RNAs interact to form the piRNA complex required for fertility in C. elegans. Molecular Cell 31:67-78. DOI: https://doi.org/10.1016/j. molcel.2008.06.002, PMID: 18571452

Beanan MJ, Strome S. 1992. Characterization of a germ-line proliferation mutation in C. elegans. Development 116:755-766. PMID: 1289064

Beltran T, Barroso C, Birkle TY, Stevens L, Schwartz HT, Sternberg PW, Fradin H, Gunsalus K, Piano F, Sharma G, Cerrato C, Ahringer J, Martínez-Pérez E, Blaxter M, Sarkies P. 2019. Comparative epigenomics reveals that RNA polymerase II pausing and chromatin domain organization control nematode piRNA biogenesis. Developmental Cell 48:793-810. DOI: https://doi.org/10.1016/j.devcel.2018.12.026, PMID: 30713076

Berkseth M, Ikegami K, Arur S, Lieb JD, Zarkower D. 2013. TRA-1 ChIP-seq reveals regulators of sexual differentiation and multilevel feedback in nematode sex determination. PNAS 110:16033-16038. DOI: https:// doi.org/10.1073/pnas.1312087110, PMID: 24046365

Bessereau J-L. 2006. Transposons in C. elegans Wormbook, the C. Elegans Research Community. WormBook.

Billi AC, Freeberg MA, Day AM, Chun SY, Khivansara V, Kim JK. 2013. A conserved upstream motif orchestrates autonomous, germline-enriched expression of Caenorhabditis elegans piRNAs. PLOS Genetics 9:e1003392. DOI: https://doi.org/10.1371/journal.pgen.1003392, PMID: 23516384

Bolger AM, Lohse M, Usadel B. 2014. Trimmomatic: a flexible trimmer for illumina sequence data. Bioinformatics 30:2114-2120. DOI: https://doi.org/10.1093/bioinformatics/btu170, PMID: 24695404

Brennecke J, Aravin AA, Stark A, Dus M, Kellis M, Sachidanandam R, Hannon GJ. 2007. Discrete small RNAgenerating loci as master regulators of transposon activity in Drosophila. Cell 128:1089-1103. DOI: https://doi. org/10.1016/j.cell.2007.01.043, PMID: 17346786

Brennecke J, Malone CD, Aravin AA, Sachidanandam R, Stark A, Hannon GJ. 2008. An epigenetic role for maternally inherited piRNAs in transposon silencing. Science 322:1387-1392. DOI: https://doi.org/10.1126/ science.1165171, PMID: 19039138

Brenner S. 1974. The genetics of Caenorhabditis elegans. Genetics 77:71-94. PMID: 4366476

Brykczynska U, Hisano M, Erkek S, Ramos L, Oakeley EJ, Roloff TC, Beisel C, Schübeler D, Stadler MB, Peters AHFM. 2010. Repressive and active histone methylation mark distinct promoters in human and mouse spermatozoa. Nature Structural \& Molecular Biology 17:679-687. DOI: https://doi.org/10.1038/nsmb.1821

Buckley BA, Burkhart KB, Gu SG, Spracklin G, Kershner A, Fritz H, Kimble J, Fire A, Kennedy S. 2012. A nuclear Argonaute promotes multigenerational epigenetic inheritance and germline immortality. Nature 489:447-451. DOI: https://doi.org/10.1038/nature11352

Carmell MA, Girard A, van de Kant HJ, Bourc'his D, Bestor TH, de Rooij DG, Hannon GJ. 2007. MIWI2 is essential for spermatogenesis and repression of transposons in the mouse male germline. Developmental Cell 12:503-514. DOI: https://doi.org/10.1016/j.devcel.2007.03.001, PMID: 17395546

Cecere G, Zheng GX, Mansisidor AR, Klymko KE, Grishok A. 2012. Promoters recognized by forkhead proteins exist for individual 21U-RNAs. Molecular Cell 47:734-745. DOl: https://doi.org/10.1016/j.molcel.2012.06.021, PMID: 22819322

Chen YA, Stuwe E, Luo Y, Ninova M, Le Thomas A, Rozhavskaya E, Li S, Vempati S, Laver JD, Patel DJ, Smibert CA, Lipshitz HD, Toth KF, Aravin AA. 2016. Cutoff suppresses RNA polymerase II termination to ensure expression of piRNA precursors. Molecular Cell 63:97-109. DOI: https://doi.org/10.1016/j.molcel.2016.05.010, PMID: 27292797

Chen P, Ellis RE. 2000. TRA-1 regulates transcription of fog-3, which controls germ cell fate in C. elegans. Development 127:3119-3129. PMID: 10862749

Choi P. 2021. SNPC-1.3. Software Heritage. swh:1:rev:b23f652341d999150edf5ae9c8de72e9192b2843. https:// archive.softwareheritage.org/swh:1:dir:31ee1e7e61bcbf6d83e27546d8bc77312a494aba;origin=https://github. com/starostikm/SNPC-1.3;visit=swh:1:snp:e969264182ce5a95f134afbd05b9042b9c6354f9; anchor=swh:1:rev: b23f652341d999150edf5ae9c8de72e9192b2843/

Clarke ND, Berg JM. 1998. Zinc fingers in Caenorhabditis elegans: finding families and probing pathways. Science 282:2018-2022. DOI: https://doi.org/10.1126/science.282.5396.2018, PMID: 9851917

Cox DN, Chao A, Baker J, Chang L, Qiao D, Lin H. 1998. A novel class of evolutionarily conserved genes defined by piwi are essential for stem cell self-renewal. Genes \& Development 12:3715-3727. DOI: https://doi.org/10. 1101/gad.12.23.3715, PMID: 9851978 
Cunningham F, Achuthan P, Akanni W, Allen J, Amode MR, Armean IM, Bennett R, Bhai J, Billis K, Boddu S, Cummins C, Davidson C, Dodiya KJ, Gall A, Girón CG, Gil L, Grego T, Haggerty L, Haskell E, Hourlier T, et al. 2019. Ensembl 2019. Nucleic Acids Research 47:D745-D751. DOl: https://doi.org/10.1093/nar/gky1113, PMID: 30407521

Das PP, Bagijn MP, Goldstein LD, Woolford JR, Lehrbach NJ, Sapetschnig A, Buhecha HR, Gilchrist MJ, Howe KL, Stark R, Matthews N, Berezikov E, Ketting RF, Tavaré S, Miska EA. 2008. Piwi and piRNAs act upstream of an endogenous siRNA pathway to suppress Tc3 transposon mobility in the Caenorhabditis elegans germline. Molecular Cell 31:79-90. DOI: https://doi.org/10.1016/j.molcel.2008.06.003, PMID: 18571451

Deng W, Lin H. 2002. Miwi, a murine homolog of piwi, encodes a cytoplasmic protein essential for spermatogenesis. Developmental Cell 2:819-830. DOI: https://doi.org/10.1016/S1534-5807(02)00165-X, PMID: 12062093

Di Giacomo M, Comazzetto S, Saini H, De Fazio S, Carrieri C, Morgan M, Vasiliauskaite L, Benes V, Enright AJ, O'Carroll D. 2013. Multiple epigenetic mechanisms and the piRNA pathway enforce LINE1 silencing during adult spermatogenesis. Molecular Cell 50:601-608. DOI: https://doi.org/10.1016/j.molcel.2013.04.026, PMID: 23706823

Doniach T, Hodgkin J. 1984. A sex-determining gene, fem-1, required for both male and hermaphrodite development in Caenorhabditis elegans. Developmental Biology 106:223-235. DOI: https://doi.org/10.1016/ 0012-1606(84)90077-0, PMID: 6541600

Fahlgren N, Sullivan CM, Kasschau KD, Chapman EJ, Cumbie JS, Montgomery TA, Gilbert SD, Dasenko M, Backman TWH, Givan SA, Carrington JC. 2009. Computational and analytical framework for small RNA profiling by high-throughput sequencing. RNA 15:992-1002. DOI: https://doi.org/10.1261/rna.1473809

Gainetdinov I, Colpan C, Arif A, Cecchini K, Zamore PD. 2018. A single mechanism of biogenesis, initiated and directed by PIWI proteins, explains piRNA production in most animals. Molecular Cell 71:775-790.

DOI: https://doi.org/10.1016/j.molcel.2018.08.007, PMID: 30193099

Girard A, Sachidanandam R, Hannon GJ, Carmell MA. 2006. A germline-specific class of small RNAs binds mammalian Piwi proteins. Nature 442:199-202. DOI: https://doi.org/10.1038/nature04917

Goh W-SS, Seah JWE, Harrison EJ, Chen C, Hammell CM, Hannon GJ. 2014. A genome-wide RNAi screen identifies factors required for distinct stages of $C$. elegans piRNA biogenesis. Genes \& Development 28:797807. DOI: https://doi.org/10.1101/gad.235622.113

Grivna ST, Beyret E, Wang Z, Lin H. 2006. A novel class of small RNAs in mouse spermatogenic cells. Genes \& Development 20:1709-1714. DOI: https://doi.org/10.1101/gad.1434406

Gu W, Lee HC, Chaves D, Youngman EM, Pazour GJ, Conte D, Mello CC. 2012. CapSeq and CIP-TAP identify pol II start sites and reveal capped small RNAs as $C$. elegans piRNA precursors. Cell 151:1488-1500.

DOI: https://doi.org/10.1016/j.cell.2012.11.023, PMID: 23260138

Hammoud SS, Low DH, Yi C, Carrell DT, Guccione E, Cairns BR. 2014. Chromatin and transcription transitions of mammalian adult germline stem cells and spermatogenesis. Cell Stem Cell 15:239-253. DOI: https://doi.org/ 10.1016/j.stem.2014.04.006, PMID: 24835570

Harris AN, Macdonald PM. 2001. Aubergine encodes a Drosophila polar granule component required for pole cell formation and related to elF2C. Development 128:2823-2832. PMID: 11526087

He L, Diedrich J, Chu YY, Yates JR. 2015. Extracting accurate precursor information for tandem mass spectra by RawConverter. Analytical Chemistry 87:11361-11367. DOI: https://doi.org/10.1021/acs.analchem.5b02721, PMID: 26499134

Henry RW, Sadowski CL, Kobayashi R, Hernandez N. 1995. A TBP-TAF complex required for transcription of human snRNA genes by RNA polymerase II and III. Nature 374:653-656. DOI: https://doi.org/10.1038/ 374653a0, PMID: 7715707

Henry RW, Mittal V, Ma B, Kobayashi R, Hernandez N. 1998. SNAP19 mediates the assembly of a functional core promoter complex (SNAPc) shared by RNA polymerases II and III. Genes \& Development 12:2664-2672. DOI: https://doi.org/10.1101/gad.12.17.2664

Hodgkin J, Horvitz HR, Brenner S. 1979. Nondisjunction mutants of the nematode Caenorhabditis elegans. Genetics 91:67-94. PMID: 17248881

Hodgkin J. 1987. A genetic analysis of the sex-determining gene, tra-1, in the nematode Caenorhabditis elegans. Genes \&amp; Development 1:731-745. DOl: https://doi.org/10.1101/gad.1.7.731

Hung K-H, Stumph WE. 2011. Regulation of snRNA gene expression by the Drosophila melanogaster small nuclear RNA activating protein complex (DmSNAPc). Critical Reviews in Biochemistry and Molecular Biology 46:11-26. DOI: https://doi.org/10.3109/10409238.2010.518136

Jawdekar G, Henry R. 2008. Transcriptional regulation of human small nuclear RNA genes. Biochimica Et Biophysica Acta (BBA) - Gene Regulatory Mechanisms 1779:295-305. DOI: https://doi.org/10.1016/j.bbagrm. 2008.04.001

Kamath R, Ahringer J. 2003. Genome-wide RNAi screening in Caenorhabditis elegans. Methods 30:313-321. DOI: https://doi.org/10.1016/S1046-2023(03)00050-1

Kaneshiro KR, Rechtsteiner A, Strome S. 2019. Sperm-inherited H3K27me3 impacts offspring transcription and development in C. elegans. Nature Communications 10:1271. DOl: https://doi.org/10.1038/s41467-019-09141w

Kasper DM, Wang G, Gardner KE, Johnstone TG, Reinke V. 2014. The C. elegans SNAPc component SNPC-4 coats piRNA domains and is globally required for piRNA abundance. Developmental Cell 31:145-158. DOI: https://doi.org/10.1016/j.devcel.2014.09.015, PMID: 25373775 
Kato M, de Lencastre A, Pincus Z, Slack FJ. 2009. Dynamic expression of small non-coding RNAs, including novel microRNAs and piRNAs/21U-RNAs, during Caenorhabditis elegans development. Genome Biology 10:R54. DOI: https://doi.org/10.1186/gb-2009-10-5-r54

Klattenhoff C, Xi H, Li C, Lee S, Xu J, Khurana JS, Zhang F, Schultz N, Koppetsch BS, Nowosielska A, Seitz H, Zamore PD, Weng Z, Theurkauf WE. 2009. The Drosophila HP1 homolog rhino is required for transposon silencing and piRNA production by dual-strand clusters. Cell 138:1137-1149. DOI: https://doi.org/10.1016/j cell.2009.07.014, PMID: 19732946

Kuramochi-Miyagawa S, Watanabe T, Gotoh K, Totoki Y, Toyoda A, Ikawa M, Asada N, Kojima K, Yamaguchi Y, Ijiri TW, Hata K, Li E, Matsuda Y, Kimura T, Okabe M, Sakaki Y, Sasaki H, Nakano T. 2008. DNA methylation of retrotransposon genes is regulated by Piwi family members MILI and MIWI2 in murine fetal testes. Genes \& Development 22:908-917. DOI: https://doi.org/10.1101/gad.1640708

Lamont LB, Kimble J. 2007. Developmental expression of FOG-1/CPEB protein and its control in the Caenorhabditis elegans hermaphrodite germ line. Developmental Dynamics 236:871-879. DOI: https://doi. org/10.1002/dvdy.21081, PMID: 17279572

Lander ES, Linton LM, Birren B, Nusbaum C, Zody MC, Baldwin J, Devon K, Dewar K, Doyle M, FitzHugh W. 2001. Initial sequencing and analysis of the human genome. Nature 409:860-921.

Langmead B, Trapnell C, Pop M, Salzberg SL. 2009. Ultrafast and memory-efficient alignment of short DNA sequences to the human genome. Genome Biology 10:R25. DOI: https://doi.org/10.1186/gb-2009-10-3-r25

Langmead B, Salzberg SL. 2012. Fast gapped-read alignment with Bowtie 2. Nature Methods 9:357-359. DOI: https://doi.org/10.1038/nmeth.1923

Levine M, Cattoglio C, Tjian R. 2014. Looping back to leap forward: transcription enters a new era. Cell 157:1325. DOI: https://doi.org/10.1016/j.cell.2014.02.009, PMID: 24679523

Li C, Harding GA, Parise J, McNamara-Schroeder KJ, Stumph WE. 2004. Architectural arrangement of cloned proximal sequence element-binding protein subunits on Drosophila U1 and U6 snRNA gene promoters. Molecular and Cellular Biology 24:1897-1906. DOI: https://doi.org/10.1128/MCB.24.5.1897-1906.2004, PMID: 14966271

Li H, Handsaker B, Wysoker A, Fennell T, Ruan J, Homer N, Marth G, Abecasis G, Durbin R, 1000 Genome Project Data Processing Subgroup. 2009. The sequence alignment/Map format and SAMtools. Bioinformatics 25:2078-2079. DOI: https://doi.org/10.1093/bioinformatics/btp352, PMID: 19505943

Li XZ, Roy CK, Dong X, Bolcun-Filas E, Wang J, Han BW, Xu J, Moore MJ, Schimenti JC, Weng Z, Zamore PD. 2013. An ancient transcription factor initiates the burst of piRNA production during early meiosis in mouse testes. Molecular Cell 50:67-81. DOI: https://doi.org/10.1016/j.molcel.2013.02.016, PMID: 23523368

Liao Y, Smyth GK, Shi W. 2014. featureCounts: an efficient general purpose program for assigning sequence reads to genomic features. Bioinformatics 30:923-930. DOI: https://doi.org/10.1093/bioinformatics/btt656

Lin H, Spradling AC. 1997. A novel group of pumilio mutations affects the asymmetric division of germline stem cells in the Drosophila ovary. Development 124:2463-2476. PMID: 9199372

Love MI, Huber W, Anders S. 2014. Moderated estimation of fold change and dispersion for RNA-seq data with DESeq2. Genome Biology 15:550. DOI: https://doi.org/10.1186/s13059-014-0550-8

Ma B, Hernandez N. 2002. Redundant cooperative interactions for assembly of a human U6 transcription initiation complex. Molecular and Cellular Biology 22:8067-8078. DOI: https://doi.org/10.1128/MCB.22.22. 8067-8078.2002, PMID: 12391172

Mittal V, Ma B, Hernandez N. 1999. SNAPc: a core promoter factor with a built-in DNA-binding damper that is deactivated by the Oct-1 POU domain. Genes \& Development 13:1807-1821. DOI: https://doi.org/10.1101/ gad.13.14.1807

Mohn F, Sienski G, Handler D, Brennecke J. 2014. The rhino-deadlock-cutoff complex licenses noncanonical transcription of dual-strand piRNA clusters in Drosophila. Cell 157:1364-1379. DOI: https://doi.org/10.1016/j. cell.2014.04.031, PMID: 24906153

Moissiard G, Bischof S, Husmann D, Pastor WA, Hale CJ, Yen L, Stroud H, Papikian A, Vashisht AA, Wohlschlegel JA, Jacobsen SE. 2014. Transcriptional gene silencing by Arabidopsis microrchidia homologues involves the formation of heteromers. PNAS 111:7474-7479. DOI: https://doi.org/10.1073/pnas.1406611111

Murchison EP, Stein P, Xuan Z, Pan H, Zhang MQ, Schultz RM, Hannon GJ. 2007. Critical roles for Dicer in the female germline. Genes \& Development 21:682-693. DOI: https://doi.org/10.1101/gad.1521307

Ozata DM, Gainetdinov I, Zoch A, O'Carroll D, Zamore PD. 2019. PIWl-interacting RNAs: small RNAs with big functions. Nature Reviews Genetics 20:89-108. DOI: https://doi.org/10.1038/s41576-018-0073-3

Paix A, Folkmann A, Rasoloson D, Seydoux G. 2015. High efficiency, Homology-Directed genome editing in Caenorhabditis elegans Using CRISPR-Cas9 Ribonucleoprotein Complexes. Genetics 201:47-54. DOI: https:// doi.org/10.1534/genetics.115.179382, PMID: 26187122

Pane A, Jiang P, Zhao DY, Singh M, Schüpbach T. 2011. The Cutoff protein regulates piRNA cluster expression and piRNA production in the Drosophila germline. The EMBO Journal 30:4601-4615. DOI: https://doi.org/10 1038/emboj.2011.334

Peng J, Elias JE, Thoreen CC, Licklider LJ, Gygi SP. 2003. Evaluation of multidimensional chromatography coupled with tandem mass spectrometry (LC/LC-MS/MS) for large-scale protein analysis: the yeast proteome. Journal of Proteome Research 2:43-50. DOI: https://doi.org/10.1021/pr025556v, PMID: 12643542

Pires-daSilva A, Sommer RJ. 2004. Conservation of the global sex determination gene tra-1 in distantly related nematodes. Genes \& Development 18:1198-1208. DOl: https://doi.org/10.1101/gad.293504

Preibisch S, Saalfeld S, Tomancak P. 2009. Globally optimal stitching of tiled 3D microscopic image acquisitions. Bioinformatics 25:1463-1465. DOI: https://doi.org/10.1093/bioinformatics/btp184 
Ramírez F, Ryan DP, Grüning B, Bhardwaj V, Kilpert F, Richter AS, Heyne S, Dündar F, Manke T. 2016. deepTools2: a next generation web server for deep-sequencing data analysis. Nucleic Acids Research 44: W160-W165. DOI: https://doi.org/10.1093/nar/gkw257

Ruby JG, Jan C, Player C, Axtell MJ, Lee W, Nusbaum C, Ge H, Bartel DP. 2006. Large-scale sequencing reveals 21U-RNAs and additional microRNAs and endogenous siRNAs in C. elegans. Cell 127:1193-1207. DOI: https:// doi.org/10.1016/j.cell.2006.10.040, PMID: 17174894

Shakes DC, Ward S. 1989. Initiation of spermiogenesis in C. elegans: A pharmacological and genetic analysis. Developmental Biology 134:189-200. DOI: https://doi.org/10.1016/0012-1606(89)90088-2

Shen EZ, Chen H, Ozturk AR, Tu S, Shirayama M, Tang W, Ding YH, Dai SY, Weng Z, Mello CC. 2018. Identification of piRNA binding sites reveals the argonaute regulatory landscape of the C. elegans Germline. Cell 172:937-951. DOI: https://doi.org/10.1016/j.cell.2018.02.002,PMID: 29456082

Shirayama M, Seth M, Lee HC, Gu W, Ishidate T, Conte D, Mello CC. 2012. piRNAs initiate an epigenetic memory of nonself RNA in the C. elegans germline. Cell 150:65-77. DOI: https://doi.org/10.1016/j.cell.2012. 06.015, PMID: 22738726

Stein L, Sternberg P, Durbin R, Thierry-Mieg J, Spieth J. 2001. WormBase: network access to the genome and biology of Caenorhabditis elegans. Nucleic Acids Research 29:82-86. DOI: https://doi.org/10.1093/nar/29.1.82

Su Y, Song Y, Wang Y, Jessop L, Zhan L, Stumph WE. 1997. Characterization of a Drosophila proximal-sequenceelement-binding protein involved in transcription of small nuclear RNA genes. European Journal of Biochemistry 248:231-237. DOI: https://doi.org/10.1111/j.1432-1033.1997.t01-1-00231.x, PMID: 9310383

Tabb DL, McDonald WH, Yates JR. 2002. DTASelect and contrast: tools for assembling and comparing protein identifications from shotgun proteomics. Journal of Proteome Research 1:21-26. DOI: https://doi.org/10.1021/ pr015504q, PMID: 12643522

Tabuchi TM, Rechtsteiner A, Jeffers TE, Egelhofer TA, Murphy CT, Strome S. 2018. Caenorhabditis elegans sperm carry a histone-based epigenetic memory of both spermatogenesis and oogenesis. Nature Communications 9:4310. DOI: https://doi.org/10.1038/s41467-018-06236-8

Timmons L, Fire A. 1998. Specific interference by ingested dsRNA. Nature 395:854. DOI: https://doi.org/10. $1038 / 27579$

Vagin VV, Sigova A, Li C, Seitz H, Gvozdev V, Zamore PD. 2006. A distinct small RNA pathway silences selfish genetic elements in the germline. Science 313:320-324. DOl: https://doi.org/10.1126/science.1129333, PMID: 16809489

Wang G, Reinke V. 2008. A C. elegans Piwi, PRG-1, Regulates 21U-RNAs during Spermatogenesis. Current Biology 18:861-867. DOI: https://doi.org/10.1016/j.cub.2008.05.009

Weick E-M, Sarkies P, Silva N, Chen RA, Moss SMM, Cording AC, Ahringer J, Martinez-Perez E, Miska EA. 2014. PRDE-1 is a nuclear factor essential for the biogenesis of Ruby motif-dependent piRNAs in C. elegans. Genes \& Development 28:783-796. DOI: https://doi.org/10.1101/gad.238105.114

Weiser NE, Yang DX, Feng S, Kalinava N, Brown KC, Khanikar J, Freeberg MA, Snyder MJ, Csankovszki G, Chan RC, Gu SG, Montgomery TA, Jacobsen SE, Kim JK. 2017. MORC-1 integrates nuclear RNAi and transgenerational chromatin architecture to promote germline immortality. Developmental Cell 41:408-423. DOI: https://doi.org/10.1016/j.devcel.2017.04.023, PMID: 28535375

Weng C, Kosalka J, Berkyurek AC, Stempor P, Feng X, Mao H, Zeng C, Li W-J, Yan Y-H, Dong M-Q, Morero NR, Zuliani C, Barabas O, Ahringer J, Guang S, Miska EA. 2019. The USTC co-opts an ancient machinery to drive piRNA transcription in C. elegans. Genes \& Development 33:90-102. DOI: https://doi.org/10.1101/gad. 319293.118

Williams Z, Morozov P, Mihailovic A, Lin C, Puvvula PK, Juranek S, Rosenwaks Z, Tuschl T. 2015. Discovery and characterization of piRNAs in the human fetal ovary. Cell Reports 13:854-863. DOI: https://doi.org/10.1016/j. celrep.2015.09.030, PMID: 26489470

Wolters DA, Washburn MP, Yates JR. 2001. An automated multidimensional protein identification technology for shotgun proteomics. Analytical Chemistry 73:5683-5690. DOI: https://doi.org/10.1021/ac010617e, PMID: 11774908

Wong MW, Henry RW, Ma B, Kobayashi R, Klages N, Matthias P, Strubin M, Hernandez N. 1998. The large subunit of basal transcription factor SNAPc is a myb domain protein that interacts with Oct-1. Molecular and Cellular Biology 18:368-377. DOI: https://doi.org/10.1128/MCB.18.1.368, PMID: 9418884

Xu T, Venable JD, Park SK, Cociorva D, Lu B, Liao L, Wohlschlegel J, Hewel J, Yates JR. 2006. ProLuCID, a fast and sensitive tandem mass spectra-based protein identification program. Mol. Cell. Proteom 5:S174.

Yang Q, Hua J, Wang L, Xu B, Zhang H, Ye N, Zhang Z, Yu D, Cooke HJ, Zhang Y, Shi Q. 2013. MicroRNA and piRNA profiles in normal human testis detected by next generation sequencing. PLOS ONE 8:e66809. DOI: https://doi.org/10.1371/journal.pone.0066809, PMID: 23826142

Yoon JB, Murphy S, Bai L, Wang Z, Roeder RG. 1995. Proximal sequence element-binding transcription factor (PTF) is a multisubunit complex required for transcription of both RNA polymerase II- and RNA polymerase IIIdependent small nuclear RNA genes. Molecular and Cellular Biology 15:2019-2027. DOI: https://doi.org/10. 1128/MCB.15.4.2019

Zanin E, Dumont J, Gassmann R, Cheeseman I, Maddox P, Bahmanyar S, Carvalho A, Niessen S, Yates JR, Oegema K, Desai A. 2011. Affinity purification of protein complexes in C. elegans. Methods in Cell Biology 106:289-322. DOI: https://doi.org/10.1016/B978-0-12-544172-8.00011-6, PMID: 22118282

Zarkower D, Hodgkin J. 1993. Zinc fingers in sex determination: only one of the two C. elegans Tra-1 proteins binds DNA in Vitro. Nucleic Acids Research 21:3691-3698. DOI: https://doi.org/10.1093/nar/21.16.3691 
Zhang Y, Liu T, Meyer CA, Eeckhoute J, Johnson DS, Bernstein BE, Nussbaum C, Myers RM, Brown M, Li W, Liu XS. 2008. Model-based Analysis of ChIP-Seq (MACS). Genome Biology 9:R137. DOI: https://doi.org/10.1186/ gb-2008-9-9-r137

Zhang L, Ward JD, Cheng Z, Dernburg AF. 2015a. The auxin-inducible degradation (AID) system enables versatile conditional protein depletion in C. elegans. Development 142:4374-4384. DOI: https://doi.org/10. 1242/dev.129635

Zhang P, Kang J-Y, Gou L-T, Wang J, Xue Y, Skogerboe G, Dai P, Huang D-W, Chen R, Fu X-D, Liu M-F, He S. 2015b. MIWI and piRNA-mediated cleavage of messenger RNAs in mouse testes. Cell Research 25:193-207. DOI: https://doi.org/10.1038/cr.2015.4

Zhang D, Tu S, Stubna M, Wu W-S, Huang W-C, Weng Z, Lee H-C. 2018. The piRNA targeting rules and the resistance to piRNA silencing in endogenous genes. Science 359:587-592. DOI: https://doi.org/10.1126/ science.aao2840

Zhou X, Zuo Z, Zhou F, Zhao W, Sakaguchi Y, Suzuki T, Suzuki T, Cheng H, Zhou R. 2010. Profiling sex-specific piRNAs in zebrafish. Genetics 186:1175-1185. DOI: https://doi.org/10.1534/genetics.110.122234, PMID: 20837 993 